09,04

\title{
Особенности спектральных характеристик различных структурных модификаций $\mathrm{Lu}_{1-x} \mathrm{RE}_{x} \mathrm{BO}_{3}$
}

\author{
() С.З. Шмурак, В.В. Кедров, А.П. Киселев, Т.Н. Фурсова, И.И. Зверькова, Е.Ю. Постнова \\ Институт фризики твердого тела им. Ю.А. Осипьяна РАН, \\ Черноголовка, Россия \\ E-mail: shmurak@issp.ac.ru
}

Поступила в Редакцию 30 апреля 2021 г.

В окончательной редакции 30 апреля 2021 г.

Принята к публикации 7 мая 2021 г.

\begin{abstract}
Проведены исследования структуры, ИК-спектров поглощения и спектров люминесценции синтезированных при $970^{\circ} \mathrm{C}$ микрокристаллов ортоборатов $\mathrm{Lu}_{1-x} \mathrm{Eu}_{x} \mathrm{BO}_{3}, \mathrm{Lu}_{0.99-x} \mathrm{~Tb}_{x} \mathrm{Eu}_{0.01} \mathrm{BO}_{3}$ и $\mathrm{Lu}_{0.99-x} \mathrm{Y}_{x} \mathrm{Eu}_{0.01} \mathrm{BO}_{3}$ при $0<x<0.25$. Увеличение $x$ приводит к последовательному изменению структурного состояния ортоборатов. При $x \leq 0.07-0.1$ соединения образуют твердый раствор со структурой кальцита и размером микрокристаллов 8-20 $\mu \mathrm{m}$, затем становятся двухфазными - наряду со структурой кальцита появляется фаза ватерита. При $x \geq 0.2-0.25$ весь объем образца имеет структуру ватерита. Установлено соответствие между структурой и спектральными характеристиками этих соединений. Исследованы спектры люминесценции при разных длинах волн возбуждающего света, что позволило получить информацию о структуре приповерхностного слоя и объема микрокристаллов исследованных образцов. Показано, что фаза ватерита появляется как в объеме крупных микрокристаллов $(8-20 \mu \mathrm{m})$, так и в виде мелких микрокристаллов $(1-2 \mu \mathrm{m})$.
\end{abstract}

Ключевые слова: люминофоры для светодиодов, ортобораты редкоземельных элементов, рентгенофазовый анализ, ИК-спектроскопия, спектры люминесценции.

DOI: 10.21883/FTT.2021.10.51414.103

\section{1. Введение}

Одним из наиболее эффективных способов направленного изменения спектральных характеристик различных полиморфных соединений боратов, молибдатов и вольфраматов, содержащих оптически активные центры, является изменение их структурного состояния, так как каждой структурной модификации соответствует строго определенный спектр свечения [1-11]. Исследование методов направленного управления спектральными характеристиками боратов редкоземельных элементов представляет значительный интерес, так как они могут быть использованы в качестве эффективных люминофоров для светодиодных источников света.

Значительные изменения спектральных характеристик ионов $\mathrm{Eu}^{3+}$ в соединениях $\mathrm{REBO}_{3}(\mathrm{Eu})$ при изменении структурного состояния боратов редкоземельных элементов позволяют использовать их в качестве структурно-чувствительных и оптически активных меток. Так как спектральные характеристики ионов $\mathrm{Eu}^{3+}$ существенно зависят от ближайшего окружения [12,13], то, как показано в работах [14-16], если ближний порядок вокруг ионов $\mathrm{Eu}^{3+}$ во всем образце одинаков, о чем свидетельствует совпадение спектров люминесценции (СЛ) приповерхностного слоя образца и его объема, то образец является однофазным.

При возбуждении свечения ионов $\mathrm{Eu}^{3+}$ в ортоборатах $\mathrm{LuBO}_{3}(\mathrm{Eu})$ светом, соответствующим области интенсивного поглощения образца, например, в полосе с переносом заряда (ПП3), $\lambda_{\mathrm{ex}}=225-275 \mathrm{~nm}[2,3,14-17]$, можно получить информацию о локальном окружении образца в приповерхностном слое кристалла. При резонансном возбуждении свечения ионов $\mathrm{Eu}^{3+}$ в области прозрачности кристалла $\left(\lambda_{\mathrm{ex}} \sim 394\right.$ и $\sim 466 \mathrm{~nm}$, электронные переходы ${ }^{7} F_{0} \rightarrow{ }^{5} L_{6}$ и ${ }^{7} F_{0} \rightarrow{ }^{5} D_{2}$ соответственно) [2,3,14-16] мы получаем информацию о ближайшем окружении ионов $\mathrm{Eu}^{3+}$ в объеме кристалла. Исследование спектральных характеристик приповерхностного слоя и объема кристалла позволило получить информацию о структуре на поверхности и в объеме микрокристаллов в твердых растворах $\mathrm{Lu}_{98-x} \operatorname{In}_{x} \mathrm{Eu}_{0.02} \mathrm{BO}_{3}$ и $\mathrm{Lu}_{0.99-x} \mathrm{Gd}_{x} \mathrm{Eu}_{0.01} \mathrm{BO}_{3}[11,18]$.

Борат лютеция $\left(\mathrm{LuBO}_{3}\right)$ имеет две устойчивые структурные модификации: ватерит (пр.гр. C2/c), который образуется при синтезе $\mathrm{LuBO}_{3}$ при $T=750-850^{\circ} \mathrm{C}$, и кальцит (пр. гр. $R \overline{3} c$ ), образующийся при $\quad T=970-1100^{\circ} \mathrm{C}$. Ортобораты $\mathrm{REBO}_{3}, \quad$ где $\mathrm{RE}=\mathrm{Eu}, \mathrm{Gd}, \mathrm{Tb}, \quad \mathrm{Dy} \quad$ и $\mathrm{Y}$ имеют только одну структурную модификацию - ватерит [19-21]. В работах [22,23] показано, что твердые растворы $\mathrm{Lu}_{1-x} \mathrm{RE}_{x} \mathrm{BO}_{3} \quad(\mathrm{RE}=\mathrm{Eu}, \quad \mathrm{Gd}, \quad \mathrm{Tb}, \quad \mathrm{Dy} \quad$ и $\mathrm{Y})$ при $x>0.15-0.2$, синтезированные при $T=970-1100^{\circ} \mathrm{C}$ (температуре существования кальцитной фазы $\mathrm{LuBO}_{3}$ ), кристаллизуются в структуре ватерита. В то же время, в работе [11] установлено, что твердый раствор $\mathrm{Lu}_{1-x} \mathrm{In}_{x} \mathrm{BO}_{3}$, состоящий из бората лютеция $\left(\mathrm{LuBO}_{3}\right)$, имеющего две устойчивые структурные модификации (ватерит и кальцит) и ортобората индия $\left(\mathrm{InBO}_{3}\right)$, 
имеющего только одну структурную модификацию (кальцит) [24-26], синтезированный при $780^{\circ} \mathrm{C}$ (температуре существования ватерита $\mathrm{LuBO}_{3}$ ) при $x>0.08-0.1$ кристаллизуется в структуре кальцита.

Исследования люминесценции соединений $\mathrm{Lu}_{0.98-x} \mathrm{In}_{x} \mathrm{Eu}_{0.02} \mathrm{BO}_{3}$. при возбуждении в полосе $\mathrm{c}$ переносом заряда $\left(\lambda_{\mathrm{ex}}=250 \mathrm{~nm}\right)$ и при резонансном возбуждении ионов $\mathrm{Eu}^{3+}\left(\lambda_{\mathrm{ex}}=394 \mathrm{~nm}\right)$, показали, что структурные преобразования в ортоборатах $\mathrm{Lu}_{0.98-x} \mathrm{In}_{x} \mathrm{Eu}_{0.02} \mathrm{BO}_{3}$ при увеличении концентрации ионов $\mathrm{In}^{3+}$ начинаются в приповерхностном слое микрокристаллов этих образцов [11]. При $x \geq 0.04$ приповерхностный слой имеет структуру кальцита, при дальнейшем увеличении концентрации индия количество фазы кальцита увеличивается и в объеме образца, а при $x>0.1$ весь образец имеет структуру кальцита.

Исследование синтезированных при $970^{\circ} \mathrm{C}$ ортоборатов $\mathrm{Lu}_{0.99-x} \mathrm{Gd}_{x} \mathrm{Eu}_{0.01} \mathrm{BO}_{3}$ показало, что с ростом концентрации $\mathrm{Gd}$ происходят изменения их структуры: при $0 \leq x \leq 0.05$ твердый раствор ортоборатов является однофазным и имеет структуру кальцита (пр.гр. $R \overline{3} c$ ); при $0.05<x \leq 0.1$ наряду со структурой кальцита появляется фаза ватерита (пр.гр. $C 2 / c$ ), а при $x>0.1$ твердый раствор является также однофазным со структурой ватерита (пр.гр. C2/c) [18]. Одновременно со структурой изменяется и морфология микрокристаллов ортоборатов. При $0 \leq x \leq 0.05$ наблюдаются крупные микрокристаллы $(15-20 \mu \mathrm{m})$, в интервале концентраций ионов $\mathrm{Gd}^{3+} 0.05<x \leq 0.1$ наряду с крупными появляются мелкие микрокристаллы $(1-2 \mu \mathrm{m})$, количество которых растет при увеличении $x$, а при $x>0.1$ наблюдаются преимущественно микрокристаллы размером $1-2 \mu \mathrm{m}$. В работе [18] показано, что микрокристаллы размером $1-2 \mu \mathrm{m}$ имеют структуру ватерита (пр.гр. C2/c). Крупные микрокристаллы $(15-20 \mu \mathrm{m})$ в ортоборатах $\mathrm{Lu}_{0.99-x} \mathrm{Gd}_{x} \mathrm{Eu}_{0.01} \mathrm{BO}_{3}$ при $0.05<x \leq 0.1$ являются двухфазными. Важно отметить, что фаза ватерита появляется при $x>0.05$ в объеме крупных микрокристаллов, имеющих структуру кальцита, и при дальнейшем увеличении концентрации ионов $\mathrm{Gd}^{3+}$ наблюдается также и на их поверхности.

Таким образом, образование кальцита в микрокристаллах $\mathrm{Lu}_{0.98-x} \operatorname{In}_{x} \mathrm{Eu}_{0.02} \mathrm{BO}_{3}$, имеющих исходную структуру ватерита, при увеличении концентрации $\mathrm{In}^{3+}$ происходит вначале в приповерхностных областях образца, в то время как образование ватерита в исходных крупных микрокристаллах $\mathrm{Lu}_{0.99-x} \mathrm{Gd}_{x} \mathrm{Eu}_{0.01} \mathrm{BO}_{3}$, имеющих структуру кальцита, осуществляется при увеличении концентрации $\mathrm{Gd}^{+}$вначале в объеме этих микрокристаллов.

Представляется важным установление того, насколько общей является наблюдаемая в образцах $\mathrm{Lu}_{0.99-x} \mathrm{Gd}_{x} \mathrm{Eu}_{0.01} \mathrm{BO}_{3}$ перестройка структуры при увеличении концентрации $\mathrm{Gd}^{3+}$. Как отмечалось, наряду с $\mathrm{GdBO}_{3}$ ортобораты ряда других редкоземельных элементов (Eu, Tb, Dy, Y и др. [19-21]) в исследуемом нами температурном интервале также имеют только одну структурную модификацию - ватерит. Выяснению изменений структуры, морфологии, ИК-спектров поглощения, а также спектров возбуждения люминесценции и спектров люминесценции твердых растворов $\mathrm{Lu}_{1-x} \mathrm{RE}_{x} \mathrm{BO}_{3}(\mathrm{RE}=\mathrm{Eu}, \mathrm{Tb}$ и $\mathrm{Y})$ при увеличении концентрации RE посвящена настоящая работа.

\section{2. Методики эксперимента}

\section{1. Синтез образцов}

Образцы поликристаллических порошков ортобората лютеция, легированного $\mathrm{Eu}^{3+}, \mathrm{Tb}^{3+}$ и $\mathrm{Y}^{3+}$, были синтезированы взаимодействием оксидов редкоземельных элементов с расплавом тетрабората калия по реакции

$$
\begin{aligned}
(1-x) \mathrm{Lu}_{2} \mathrm{O}_{3} & +x \mathrm{RE}_{2} \mathrm{O}_{3} \\
& +\mathrm{K}_{2} \mathrm{~B}_{4} \mathrm{O}_{7}=2 \mathrm{Lu}_{1-x} \mathrm{RE}_{x} \mathrm{BO}_{3}+\mathrm{K}_{2} \mathrm{~B}_{2} \mathrm{O}_{4} .
\end{aligned}
$$

Количество тетрабората калия, взятое в реакцию, обеспечивало избыток борсодержащего реагента относительно стехиометрического количества на 10-20\%. Исходными соединениями для синтеза ортобората лютеция были тетраборат калия $\mathrm{K}_{2} \mathrm{~B}_{4} \mathrm{O}_{7} \cdot 4 \mathrm{H}_{2} \mathrm{O}$, оксиды $\mathrm{Lu}_{2} \mathrm{O}_{3}$, $\mathrm{Eu}_{2} \mathrm{O}_{3}, \mathrm{~Tb}_{2} \mathrm{O}_{3}, \mathrm{Y}_{2} \mathrm{O}_{3}$ и азотная кислота. Все использованные химические вещества соответствовали квалификации „ЧДА“. Ионы $\mathrm{Lu}^{3+}, \mathrm{Eu}^{3+} \mathrm{Tb}^{3+}$ и $\mathrm{Y}^{3+}$ вводили в реакцию в виде водных растворов их нитратных солей, которые получали растворением исходных оксидов редких земель в азотной кислоте. Синтез микрокристаллических порошков ортобората лютеция, легированного $\mathrm{Eu}^{3+}, \mathrm{Tb}^{3+}$ и $\mathrm{Y}^{3+}$, проводился следующим образом. Взвешенное количество кристаллического тетрабората калия (гидрата) и соответствующий объем калиброванного водного раствора нитратов редких земель помещали в керамическую чашку и тщательно перемешивали. Полученную водную суспензию нагревали на плитке и при осторожном кипении отгоняли воду. Полученный твердый продукт отжигали при температуре $600^{\circ} \mathrm{C}$ в течение $20 \mathrm{~min}$ для удаления остаточной влаги и разложения нитратных солей. Твердый продукт-прекурсор перетирали в агатовой ступке и полученный порошок переносили или в керамический тигель объемом $5 \mathrm{ml}$, или в металлическую цилиндрическую пресс-форму для формования порошка в виде таблеток диаметром $15 \mathrm{~mm}$ и толщиной $2.0-2.5 \mathrm{~mm}$ при давлении $5 \mathrm{Kbar}$. Обе формы прекурсора (порошок и таблетка) подвергали высокотемпературному отжигу при $T=970^{\circ} \mathrm{C}$ в течение 2 h. Полученные продукты обрабатывались водным раствором соляной кислоты с концентрацией $5 \mathrm{wt} \%$ в течение $0.2 \mathrm{~h}$. Выделение поликристаллов ортоборатов проводилось фильтрованием полученной водной суспензии с последующей промывкой водой, спиртом и сушкой продукта на фильтре. Полученные порошки поликристаллов ортоборатов окончательно сушились на воздухе при $T=200^{\circ} \mathrm{C}$ в течение $0.5 \mathrm{~h}$. 
Процедура прессования проводилась с целью выяснения влияния исходной плотности продукта-прекурсора (порошок или таблетка) на морфологию получившихся микрокристаллов ортоборатов.

\section{2. Методы исследований}

Рентгенодифракционные исследования проводили с использованием дифрактометра Rigaku SmartLab SE на $\mathrm{Cu} K_{\alpha}$-излучении, $\lambda=1.54178 \AA, 40 \mathrm{kV}, 35 \mathrm{~mA}$. Угловой интервал $2 \theta=10-140^{\circ}$. Фазовый анализ образцов и расчет параметров решетки проводили с использованием программ Match и PowderCell 2.4.

ИК-спектры поглощения образцов измерялись на Фурье-спектрометре VERTEX 80v в спектральном диапазоне $400-5000 \mathrm{~cm}^{-1}$ с разрешением $2 \mathrm{~cm}^{-1}$. Для измерений порошки поликристаллов перетирались в агатовой ступке, а затем тонким слоем наносились на кристаллическую шлифованную подложку $\mathrm{KBr}$.

Морфология образцов изучалась с использованием рентгеновского микроанализатора Supra 50VP с приставкой для EDS INCA (Oxford).

Спектры фотолюминесценции и спектры возбуждения люминесценции изучались на установке, состоящей из источника света - лампы ДКСШ-150, двух монохроматоров МДР-4 и МДР-6 (спектральный диапазон 200-1000 nm, дисперсия $1.3 \mathrm{~nm} / \mathrm{mm}$ ). Регистрация свечения осуществлялась фотоумножителем ФЭУ-106 (область спектральной чувствительности 200-800 nm) и усилительной системой. Монохроматор МДР-4 использовался для изучения спектров возбуждения люминесценции образцов, монохроматор МДР-6 применялся для изучения спектров люминесценции.

Спектральные и структурные характеристики, а также морфология образцов, исследовались при комнатной температуре.

\section{3. Рентгеноструктурные исследования}

Дифрактограммы порошковых образцов исследуемых соединений $\mathrm{Lu}_{1-x} \mathrm{RE}_{x} \mathrm{BO}_{3} \quad(\mathrm{RE}=\mathrm{Eu}$, $\mathrm{Tb}$ и $\mathrm{Y}$ ) представлены на рис. 1. Фазовый состав образцов приведен в табл. 1. Ортобораты $\mathrm{Lu}_{1-x} \mathrm{Eu}_{x} \mathrm{BO}_{3}$ при $0 \leq x \leq 0.07, \mathrm{Lu}_{0.99-x} \mathrm{~Tb}_{x} \mathrm{Eu}_{0.01} \mathrm{BO}_{3}$ при $\quad 0 \leq x \leq 0.09, \quad$ а $\quad \mathrm{Lu}_{0.99-x} \mathrm{Y}_{x} \mathrm{Eu}_{0.01} \mathrm{BO}_{3} \quad$ при $0 \leq x \leq 0.10$ являются однофазными и имеют структуру кальцита (PDF 72-1053) - ромбоэдрическую, $R \overline{3} c \quad$ (пр.гр. № 167), $Z=6$. Твердые растворы $\mathrm{Lu}_{1-x} \mathrm{Eu}_{x} \mathrm{BO}_{3}$ при $0.07<x<0.2, \mathrm{Lu}_{0.99-x} \mathrm{~Tb}_{x} \mathrm{Eu}_{0.01} \mathrm{BO}_{3}$ при $\quad 0.09<x<0.2, \quad$ a $\quad \mathrm{Lu}_{0.99-x} \mathrm{Y}_{x} \mathrm{Eu}_{0.01} \mathrm{BO}_{3} \quad$ при $0.1<x<0.25$ являются двухфазными - наряду со структурой кальцита наблюдается фаза ватерита моноклинная, $C 2 / c$ (пр.гр. № 15), $Z=12$ [27]. Как видно из табл. 1 , количество фазы ватерита растет с увеличением концентрации ионов $\mathrm{RE}^{3+}$. Соединения $\mathrm{Lu}_{1-x} \mathrm{Eu}_{x} \mathrm{BO}_{3} \quad$ и $\mathrm{Lu}_{0.99-x} \mathrm{~Tb}_{x} \mathrm{Eu}_{0.01} \mathrm{BO}_{3}$ при $x \geq 0.2$, а
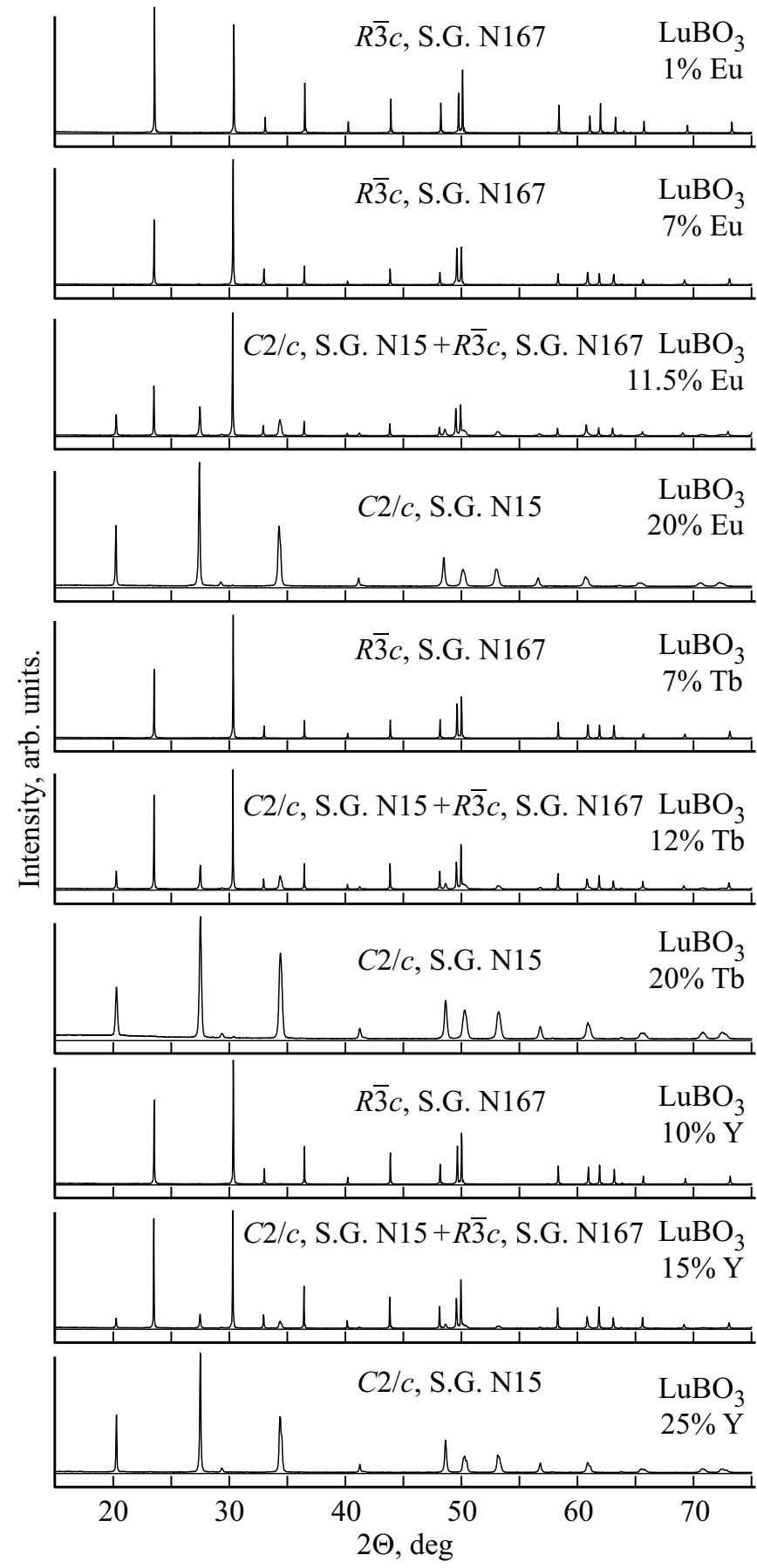

Рис. 1. Дифрактограммы образцов $\mathrm{Lu}_{1-x} \mathrm{RE}_{x} \mathrm{BO}_{3}$ $(\mathrm{RE}=\mathrm{Eu}, \mathrm{Tb}$ и $\mathrm{Y})(0 \leq x \leq 0.25)$.

$\mathrm{Lu}_{0.99-x} \mathrm{Y}_{x} \mathrm{Eu}_{0.01} \mathrm{BO}_{3}$ при $x \geq 0.25$ снова становятся однофазными и имеют структуру ватерита (табл. 1).

Таким образом, в ортоборатах $\mathrm{Lu}_{1-x} \mathrm{RE}_{x} \mathrm{BO}_{3}$ $(\mathrm{RE}=\mathrm{Eu}, \quad \mathrm{Tb} \quad$ и $\mathrm{Y}), \quad$ как $\quad$ и $\quad$ в соединениях $\mathrm{Lu}_{0.99-x} \mathrm{Gd}_{x} \mathrm{Eu}_{0.01} \mathrm{BO}_{3}$, можно выделить три области концентраций RE, в которых существуют определенные структурные состояния. C ростом концентрации RE происходит последовательная смена двух типов кристаллических фаз. Вначале твердый раствор $\mathrm{Lu}_{1-x} \mathrm{RE}_{x} \mathrm{BO}_{3}$ 
Таблица 1. Влияние концентрации $\mathrm{RE}^{3+}$ на содержание фаз кальцита и ватерита в ортоборатах $\mathrm{Lu}_{1-x} \mathrm{RE}_{x} \mathrm{BO}_{3}$ $(\mathrm{RE}=\mathrm{Eu}, \mathrm{Tb}, \mathrm{Y})$

\begin{tabular}{c|c|c}
\hline $\mathrm{Lu}_{1-x} \mathrm{RE}_{x} \mathrm{BO}_{3}$ & Фаза кальцита & Фаза ватерита \\
$(\mathrm{RE}=\mathrm{Eu}, \mathrm{Tb}, \mathrm{Y}) \mathrm{RE}$, at.\% & (S.G. № 167), \% & (S.G. № 15), \% \\
\hline $\mathrm{Eu}, 1$ & 100 & 0 \\
$\mathrm{Eu}, 7$ & 100 & 0 \\
$\mathrm{Eu}, 9$ & 86.5 & 13.5 \\
$\mathrm{Eu}, 11.5$ & 36 & 64 \\
$\mathrm{Eu}, 15$ & 4 & 96 \\
$\mathrm{Eu}, 20$ & 0 & 100 \\
$\mathrm{~Tb}, 7$ & 100 & 0 \\
$\mathrm{~Tb}, 9.5$ & 96.5 & 3.5 \\
$\mathrm{~Tb}, 10.5$ & 79 & 21 \\
$\mathrm{~Tb}, 12$ & 72 & 28 \\
$\mathrm{~Tb}, 15$ & 14 & 86 \\
$\mathrm{~Tb}, 20$ & 0 & 100 \\
$\mathrm{Y}, 10$ & 100 & 0 \\
$\mathrm{Y}, 15$ & 80 & 20 \\
$\mathrm{Y}, 20$ & 10 & 90 \\
$\mathrm{Y}, 25$ & 0 & 100 \\
${ }^{*} \mathrm{Eu}, 9$ & 100 & 0 \\
${ }^{*} \mathrm{Eu}, 15$ & 25 & 75 \\
${ }^{* *} \mathrm{~Tb}, 14$ & 39 & 61 \\
${ }^{* *} \mathrm{~Tb}, 16$ & 0 & 100 \\
${ }^{*} \mathrm{Y}, 15$ & 52 & 48 \\
${ }^{*} \mathrm{Y}, 20$ & 4.5 & 95.5 \\
& &
\end{tabular}

Примечани е. * Образцы, подвергнутые прессованию перед отжигом. ${ }^{* *}$ Данные работы [10].

$(\mathrm{RE}=\mathrm{Eu}, \mathrm{Tb}$ и $\mathrm{Y})$ имеет структуру кальцита, затем при увеличении концентрации $\mathrm{RE}$ соединение $\mathrm{Lu}_{1-x} \mathrm{RE}_{x} \mathrm{BO}_{3}$ становится двухфазным, наряду со структурой кальцита появляется фаза ватерита, а при дальнейшем увеличении концентрации RE твердый раствор имеет структуру ватерита (табл. 2).

Важно отметить, что интервалы концентраций легирующих редкоземельных элементов $(x)$, при которых

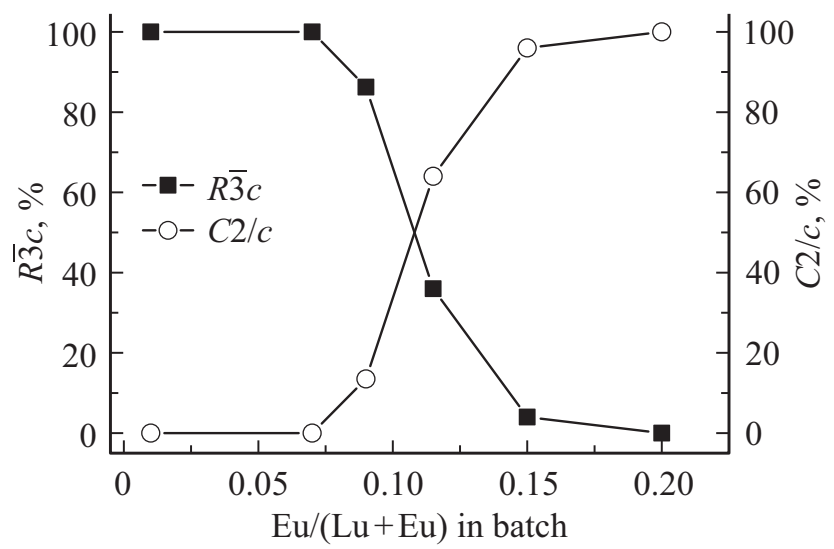

Рис. 2. Фазовый состав синтезированных образцов $\mathrm{Lu}_{1-x} \mathrm{Eu}_{x} \mathrm{BO}_{3}$ в зависимости от соотношения редких земель в шихте при $0 \leq x \leq 0.2$. происходят изменения структурных состояний, в ортобоpaтах $\mathrm{Lu}_{1-x} \mathrm{RE}_{x} \mathrm{BO}_{3}(\mathrm{RE}=\mathrm{Eu}, \mathrm{Tb}$ и $\mathrm{Y})$ заметно больше, чем в $\mathrm{Lu}_{0.99-x} \mathrm{Gd}_{x} \mathrm{Eu}_{0.01} \mathrm{BO}_{3}$ (табл. 2).

Изменение фазового состава $\mathrm{Lu}_{1-x} \mathrm{Eu}_{x} \mathrm{BO}_{3}$ при увеличении концентрации $\mathrm{Eu}^{3+}$ приведено на рис. 2. Как видно из рис. 2 , предел растворимости ионов $\mathrm{Eu}^{3+}$ в кальцитной (ромбоэдрической) модификации $\mathrm{LuBO}_{3}$ составляет $\sim 7$ at.\%, а предел растворимости ионов $\mathrm{Lu}^{3+}$ в ватеритной (моноклинной) модификации $\mathrm{EuBO}_{3}$ составляет $\sim 80$ at.\%. Подобные зависимости изменения фазового состава получены для ортоборатов $\mathrm{Lu}_{0.99-x} \mathrm{~Tb}_{x} \mathrm{Eu}_{0.01} \mathrm{BO}_{3}$ и $\mathrm{Lu}_{0.99-x} \mathrm{Y}_{x} \mathrm{Eu}_{0.01} \mathrm{BO}_{3}$. Пределы растворимости ионов $\mathrm{Tb}^{3+}$ и $\mathrm{Y}^{3+}$ в ромбоэдрической модификации $\mathrm{LuBO}_{3}$ составляют $\sim 9$ и 10 at.\%, а пределы растворимости ионов $\mathrm{Lu}^{3+}$ в моноклинной модификации $\mathrm{TbBO}_{3}$ и $\mathrm{YBO}_{3}$ составляют $\sim 80$ и 75 at.\% соответственно. Значительные различия в пределах растворимости ионов $\mathrm{Eu}^{3+}$, $\mathrm{Tb}^{3+}, \mathrm{Y}^{3+}$ в $\mathrm{LuBO}_{3}$ и ионов $\mathrm{Lu}^{3+}$ в $\mathrm{EuBO}_{3}, \mathrm{TbBO}_{3}$, $\mathrm{YBO}_{3}$ связаны с тем, что ионный радиус $\mathrm{Lu}^{3+}(0.867 \AA)$ заметно меньше ионных радиусов ионов $\mathrm{Eu}^{3+}(0.987 \AA)$, $\mathrm{Tb}^{3+}(0.956 \AA), \mathrm{Y}^{3+}(0.928 \AA)[28]$.

Следует отметить, что подобные изменения фазового состава наблюдались нами ранее в молибдатах $\left(\mathrm{Lu}_{1-x} \mathrm{Eu}_{x}\right)_{2}\left(\mathrm{MoO}_{4}\right)_{3} \quad$ и $\quad$ вольфраматах $\left(\mathrm{Lu}_{1-x} \mathrm{Eu}_{x}\right)_{2}\left(\mathrm{WO}_{4}\right)_{3}[29,30]$.

\section{4. Морфология образцов}

\section{1. Морфология ортоборатов $\mathrm{Lu}_{1-x} \mathrm{Eu}_{x} \mathrm{BO}_{3}$ и $\mathrm{Lu}_{0.99-x} \mathrm{~Tb}_{x} \mathrm{Eu}_{0.01} \mathrm{BO}_{3}$}

В образцах $\mathrm{Lu}_{1-x} \mathrm{Eu}_{x} \mathrm{BO}_{3}$ и $\mathrm{Lu}_{0.99-x} \mathrm{~Tb}_{x} \mathrm{Eu}_{0.01} \mathrm{BO}_{3}$ в диапазоне концентраций $\mathrm{Eu}^{3+} 0 \leq x \leq 0.07$ и $\mathrm{Tb}^{3+}$ $0 \leq x \leq 0.09$ соответственно, имеющих согласно данным рентгенофазового анализа структуру кальцита (табл. 1), наблюдаются крупные микрокристаллы размером $\sim 15-20 \mu \mathrm{m}$ (рис. $3, a, f)$. При увеличении концентрации европия (тербия) наряду с крупными микрокристаллами, появляются мелкие микрокристаллы размером $\sim 1-2 \mu \mathrm{m}$. С ростом концентрации ионов $\mathrm{Eu}^{3+}\left(\mathrm{Tb}^{3+}\right)$ количество мелких микрокристаллов увеличивается, а крупных уменьшается, при этом растет количество фазы ватерита (рис. $3, b, c ; g, h$ и $k$ ). В образцах $\mathrm{Lu}_{0.8} \mathrm{Eu}_{0.2} \mathrm{BO}_{3}$ и $\mathrm{Lu}_{0.79} \mathrm{~Tb}_{0.2} \mathrm{Eu}_{0.01} \mathrm{BO}_{3}$, имеющих структуру ватерита (табл. 1), наблюдается подавляющее большинство мелких микрокристаллов (рис. $3, d$ и $l$ ).

Таким образом, на основании исследований фазового состава образцов $\mathrm{Lu}_{0.8} \mathrm{Eu}_{0.2} \mathrm{BO}_{3}$ и $\mathrm{Lu}_{0.79} \mathrm{~Tb}_{0.2} \mathrm{Eu}_{0.01} \mathrm{BO}_{3}$, можно предположить, что в соединениях $\mathrm{Lu}_{1-x} \mathrm{Eu}_{x} \mathrm{BO}_{3}$ и $\mathrm{Lu}_{0.99-x} \mathrm{~Tb}_{x} \mathrm{Eu}_{0.01} \mathrm{BO}_{3}$, также как и в образцах $\mathrm{Lu}_{0.99-x} \mathrm{Gd}_{x} \mathrm{Eu}_{0.01} \mathrm{BO}_{3}$ [18], микрокристаллы, размер которых составляет $1-2 \mu \mathrm{m}$, имеют структуру ватерита.

Оценка соотношения объемов мелких и крупных микрокристаллов на рис. $3, b, c, h, k$ и $l$ (в образцах $\mathrm{Lu}_{0.91} \mathrm{Eu}_{0.09} \mathrm{BO}_{3}, \mathrm{Lu}_{0.885} \mathrm{Eu}_{0.115} \mathrm{BO}_{3}, \mathrm{Lu}_{0.87} \mathrm{~Tb}_{0.12} \mathrm{Eu}_{0.01} \mathrm{BO}_{3}$ 
Таблица 2. Области концентраций $\mathrm{RE}$, в которых существуют определенные структурные состояния ортоборатов $\mathrm{Lu}_{1-x} \mathrm{RE}_{x} \mathrm{BO}_{3}$ $(\mathrm{RE}=\mathrm{Eu}, \mathrm{Tb}$ и $\mathrm{Y})$

\begin{tabular}{c|c|c|c}
\hline \multirow{2}{*}{ Соединение } & \multicolumn{3}{|c}{ Значения $x$, при которых существуют указанные структуры } \\
\cline { 2 - 4 } & Кальцит $(R \overline{3} c)$ & Кальцит $(R \overline{3} c)+$ ватерит $(C 2 / c)$ & Ватерит $(C 2 / c)$ \\
\hline $\mathrm{Lu}_{1-x} \mathrm{Eu}_{x} \mathrm{BO}_{3}$ & $0 \leq x \leq 0.07$ & $0.07<x<0.2$ & $x \geq 0.2$ \\
$\mathrm{Lu}_{0.99-x} \mathrm{~Tb}_{x} \mathrm{Eu}_{0.01} \mathrm{BO}_{3}$ & $0 \leq x \leq 0.09$ & $0.09<x<0.2$ & $x \geq 0.2$ \\
$\mathrm{Lu}_{0.99-x} \mathrm{Y}_{x} \mathrm{Eu}_{0.01} \mathrm{BO}_{3}$ & $0 \leq x \leq 0.10$ & $0.1<x<0.25$ & $x \geq 0.25$ \\
${ }^{*} \mathrm{Lu}_{0.99-x} \mathrm{Gd}_{x} \mathrm{Eu}_{0.01} \mathrm{BO}_{3}$ & $0 \leq x \leq 0.05$ & $0.05<x \leq 0.1$ & $x>0.1$
\end{tabular}

Примечание. * Данные работы [18].

$a$

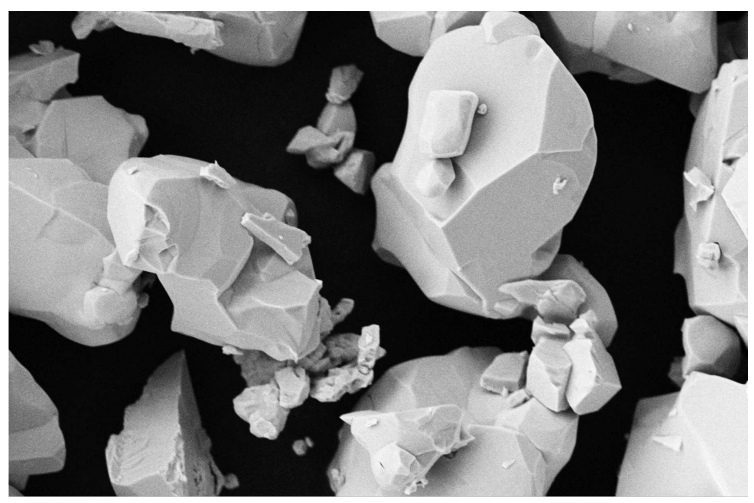

$-3 \mu \mathrm{m}$

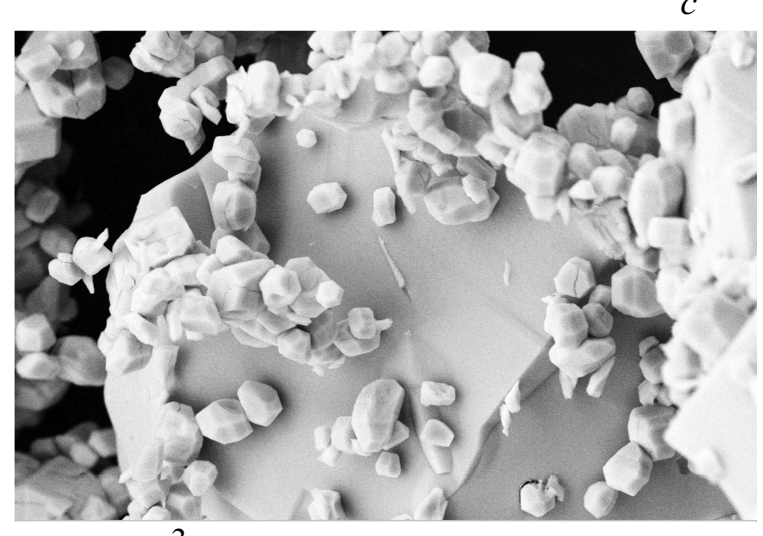

$-3 \mu \mathrm{m}$

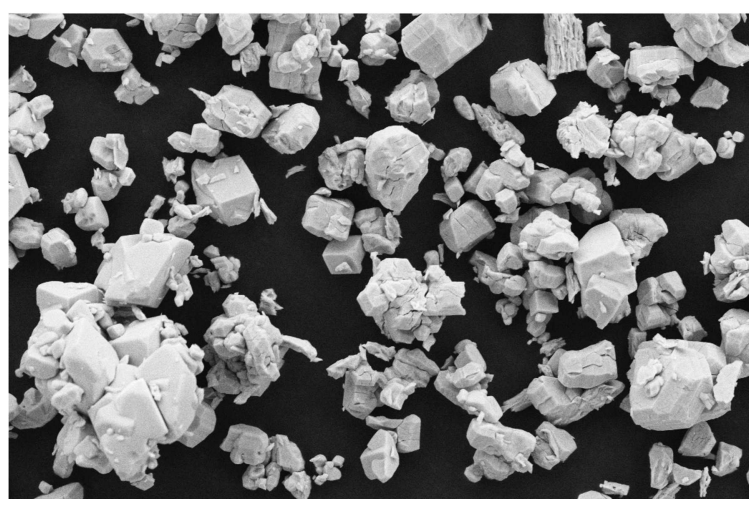

$-3 \mu \mathrm{m}$

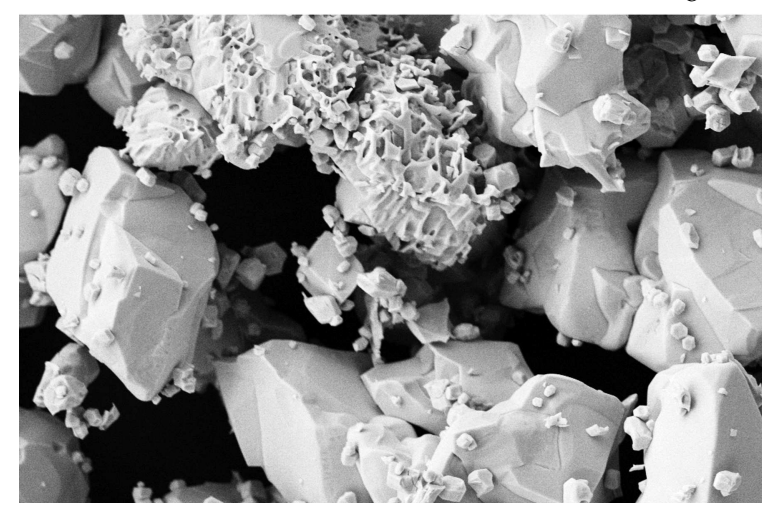

$-3 \mu \mathrm{m}$

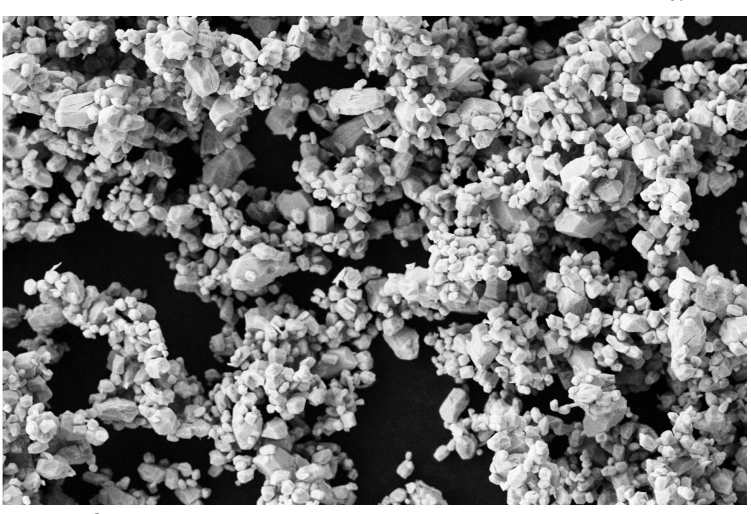

$-3 \mu \mathrm{m}$

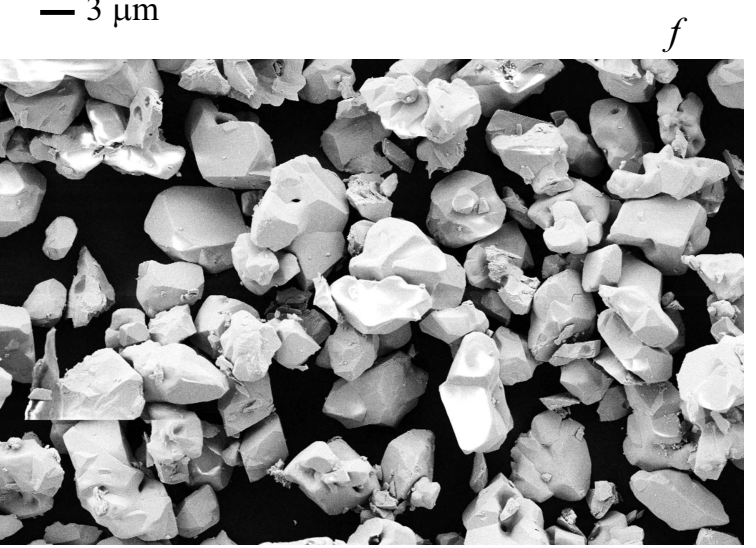

$-10 \mu \mathrm{m}$

Рис. 3. Морфология образцов $\mathrm{Lu}_{1-x} \mathrm{Eu}_{x} \mathrm{BO}_{3} \quad$ и $\mathrm{Lu}_{0.99-x} \mathrm{~Tb}_{x} \mathrm{Eu}_{0.01} \mathrm{BO}_{3} . \quad a-\mathrm{Lu}_{0.93} \mathrm{Eu}_{0.07} \mathrm{BO}_{3} ; \quad b-\mathrm{Lu}_{0.91} \mathrm{Eu}_{0.09} \mathrm{BO}_{3} ; c-$ $\mathrm{Lu}_{0.885} \mathrm{Eu}_{0.115} \mathrm{BO}_{3} ; d-\mathrm{Lu}_{0.8} \mathrm{Eu}_{0.2} \mathrm{BO}_{3} ; e-{ }^{*} \mathrm{Lu}_{0.85} \mathrm{Eu}_{0.15} \mathrm{BO}_{3} ; f-\mathrm{Lu}_{0.92} \mathrm{~Tb}_{0.07} \mathrm{Eu}_{0.01} \mathrm{BO}_{3} ; g-\mathrm{Lu}_{0.885} \mathrm{~Tb}_{0.105} \mathrm{Eu}_{0.01} \mathrm{BO}_{3} ; h-$ $\mathrm{Lu}_{0.87} \mathrm{~Tb}_{0.12} \mathrm{Eu}_{0.01} \mathrm{BO}_{3} ; k-\mathrm{Lu}_{0.84} \mathrm{~Tb}_{0.15} \mathrm{Eu}_{0.01} \mathrm{BO}_{3} ; l-\mathrm{Lu}_{0.79} \mathrm{~Tb}_{0.2} \mathrm{Eu}_{0.01} \mathrm{BO}_{3} ; m-{ }^{*} \mathrm{Lu}_{0.85} \mathrm{~Tb}_{0.14} \mathrm{Eu}_{0.01} \mathrm{BO}_{3} ; n-{ }^{*} \mathrm{Lu}_{0.83} \mathrm{~Tb}_{0.16} \mathrm{Eu}_{0.01} \mathrm{BO}_{3}$ (e, $m$ и $n-$ образцы, подвергнутые прессованию перед отжигом). 
$g$

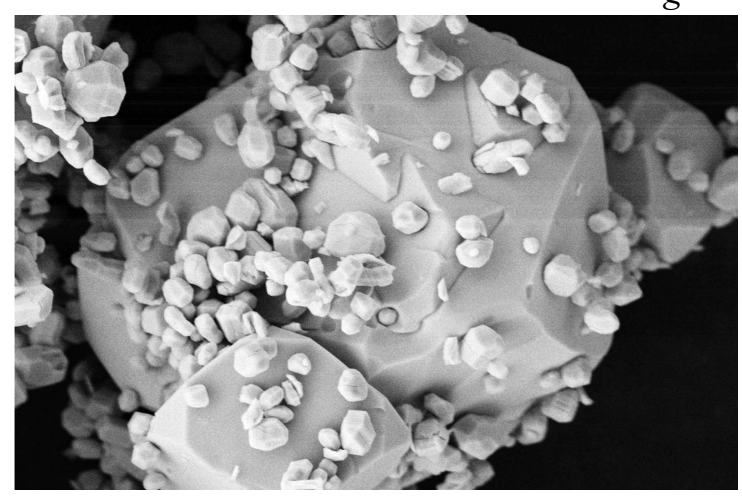

$-3 \mu \mathrm{m}$

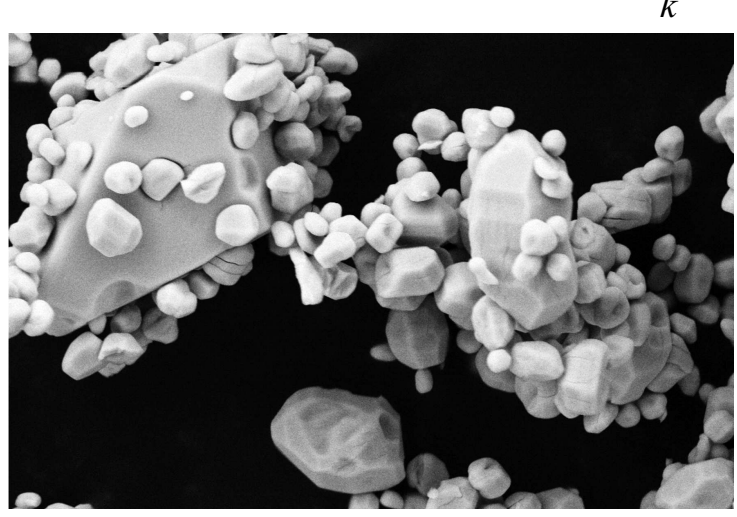

$-3 \mu \mathrm{m}$

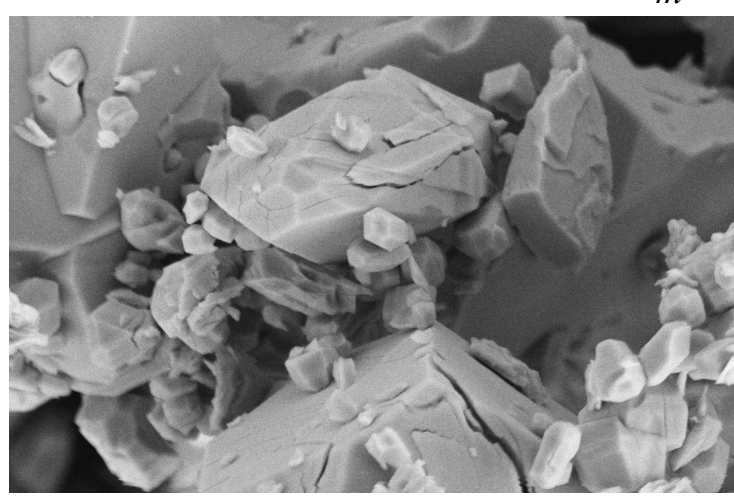

$3 \mu \mathrm{m}$

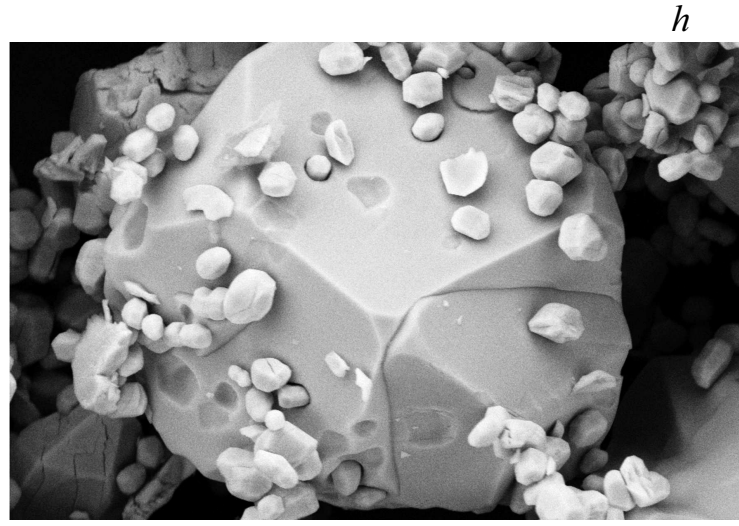

$-3 \mu \mathrm{m}$

l

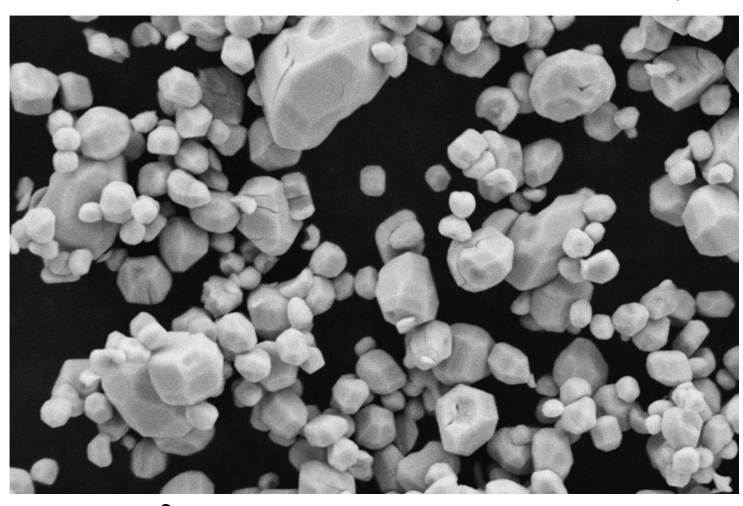

$-3 \mu \mathrm{m}$

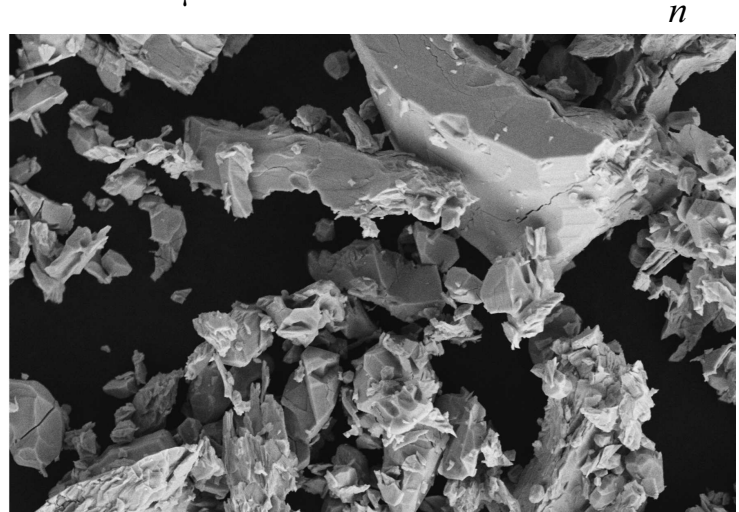

$-3 \mu \mathrm{m}$

Рис. 3 (продолжение).

и $\left.\mathrm{Lu}_{0.84} \mathrm{~Tb}_{0.15} \mathrm{Eu}_{0.01} \mathrm{BO}_{3}\right)$ показала, что количество мелких микрокристаллов, представляющих фазу ватерита, составляет $\sim 0.4,6-7,3-4$ и 13-14\% соответственно. В то же время, согласно данным рентгенофазового анализа, количество фазы ватерита в этих образцах значительно больше и составляет 13.5, 64, 28 и $86 \%$ соответственно (табл. 1). Это свидетельствует о том, что крупные микрокристаллы $(15-20 \mu \mathrm{m})$ в соединениях $\mathrm{Lu}_{1-x} \mathrm{Eu}_{x} \mathrm{BO}_{3}$ при $0.07<x<0.2$ и $\mathrm{Lu}_{0.99-x} \mathrm{~Tb}_{x} \mathrm{Eu}_{0.01} \mathrm{BO}_{3}$ при $0.09<x<0.2$, также как и в образцах $\mathrm{Lu}_{0.99-x} \mathrm{Gd}_{x} \mathrm{Eu}_{0.01} \mathrm{BO}_{3}$ при $0.05<x \leq 0.1$, являются двухфазными и содержат фазы ватерита и кальцита.
Следует отметить, что соотношение между количеством мелких и крупных микрокристаллов существенно зависит от способа синтеза образца. Если перед отжигом при $970^{\circ} \mathrm{C}$ шихта подвергнута прессованию, то в образцах ${ }^{*} \mathrm{Lu}_{0.85} \mathrm{Eu}_{0.15} \mathrm{BO}_{3} ;{ }^{*} \mathrm{Lu}_{0.85} \mathrm{~Tb}_{0.14} \mathrm{Eu}_{0.01} \mathrm{BO}_{3}$ и ${ }^{*} \mathrm{Lu}_{0.83} \mathrm{~Tb}_{0.16} \mathrm{Eu}_{0.01} \mathrm{BO}_{3}$, содержащих 75, 61 и $100 \%$ ватерита, подавляющее большинство микрокристаллов имеет размер $8-12 \mu \mathrm{m}$, а мелких микрокристаллов размером $1-2 \mu \mathrm{m}$ во много раз меньше, чем в образцах, предварительно не подвергнутых прессованию (рис. 3,e, $m, n$ ). Это свидетельствует о том, что в соединениях ${ }^{*} \mathrm{Lu}_{0.85} \mathrm{Eu}_{0.15} \mathrm{BO}_{3}$ и ${ }^{*} \mathrm{Lu}_{0.85} \mathrm{~Tb}_{0.14} \mathrm{Eu}_{0.01} \mathrm{BO}_{3}$, полученных после отжига при $970^{\circ} \mathrm{C}$ спрессованных таб- 
леток, микрокристаллы, размер которых равен 8-12 $\mu \mathrm{m}$, являются двухфазными. При $x \geq 0.16$ микрокристаллы $(8-12 \mu \mathrm{m})$ в образцах ${ }^{*} \mathrm{Lu}_{0.99-x} \mathrm{~Tb}_{x} \mathrm{Eu}_{0.01} \mathrm{BO}_{3}$ имеют структуру ватерита (рис. $3, n$ ), в то время как в предварительно не спрессованных образцах $\mathrm{Lu}_{0.99-x} \mathrm{~Tb}_{x} \mathrm{Eu}_{0.01} \mathrm{BO}_{3}$ после отжига при $970^{\circ} \mathrm{C}$ структуру ватерита имеют микрокристаллы размером $1-2 \mu \mathrm{m}$ (рис. $3, l$ ).

\section{2. Морфология ортоборатов $\mathrm{Lu}_{0.99-x} \mathrm{Y}_{x} \mathrm{Eu}_{0.01} \mathrm{BO}_{3}$}

Образцы ортоборатов $\mathrm{Lu}_{0.99-x} \mathrm{Y}_{x} \mathrm{Eu}_{0.01} \mathrm{BO}_{3}$ при $0 \leq x \leq 0.1$, которые имеют, согласно данным рентгенофазового анализа структуру кальцита (табл. 1), состоят из крупных микрокристаллов размером $\sim 15-20 \mu \mathrm{m}$ (рис. 4,a). При $x>0.1$ наблюдаются преимущественно микрокристаллы размером 8-18 $\mu \mathrm{m}$, а объем мелких микрокристаллов размером $1-2 \mu \mathrm{m}$ во много раз меньше объема крупных микрокристаллов (рис. 4,b,c и $d$ ). Наибольшее количество микрокристаллов $1-2 \mu \mathrm{m}$ наблюдается в образцах $\mathrm{Lu}_{0.84} \mathrm{Y}_{0.15} \mathrm{Eu}_{0.01} \mathrm{BO}_{3}$ (рис. 4, $b$ ). Оценка соотношения объемов мелких и крупных микрокристаллов в этих образцах на рис. 4, $b$, показала, что количество мелких микрокристаллов, представляющих фазу ватерита, даже в этих образцах составляет $\sim 1 \%$. В то же время, согласно данным рентгенофазового анализа, количество фазы ватерита в этих образцах значительно больше и составляет $20 \%$ (табл. 1). Это свидетельствует о том, что крупные микрокристаллы $(8-18 \mu \mathrm{m})$ в соединении $\mathrm{Lu}_{0.84} \mathrm{Y}_{0.15} \mathrm{Eu}_{0.01} \mathrm{BO}_{3}$ являются двухфазными и содержат фазы ватерита и кальцита.

Согласно данным рентгенофазового анализа при $0.1<x<0.25$ соединения $\mathrm{Lu}_{0.99-x} \mathrm{Y}_{x} \mathrm{Eu}_{0.01} \mathrm{BO}_{3}$ являются двухфазными, поэтому микрокристаллы $(8-18 \mu \mathrm{m})$ этих соединений также являются двухфазными. При $x \geq 0.25$ образцы $\mathrm{Lu}_{0.99-x} \mathrm{Y}_{x} \mathrm{Eu}_{0.01} \mathrm{BO}_{3}$ имеют структуру ватерита (табл. 1), поэтому и микрокристаллы размером 8-20 $\mu \mathrm{m}$ являются однофазными и имеют структуру ватерита. В этих микрокристаллах наблюдаются множественные нарушения сплошности в виде трещин (рис. $4, c, d$ и $e$ ).

Следует отметить, что, в отличие от ортоборатов $\mathrm{Lu}_{1-x} \mathrm{Eu}_{x} \mathrm{BO}_{3}$ и $\mathrm{Lu}_{0.99-x} \mathrm{~Tb}_{x} \mathrm{Eu}_{0.01} \mathrm{BO}_{3}$, прессование таблеток $\mathrm{Lu}_{0.99-x} \mathrm{Y}_{x} \mathrm{Eu}_{0.01} \mathrm{BO}_{3}$ перед отжигом при $970^{\circ} \mathrm{C}$ практически не влияет на морфологию этих образцов. В подвергнутых прессованию перед отжигом образцах $\mathrm{Lu}_{0.99-x} \mathrm{Y}_{x} \mathrm{Eu}_{0.01} \mathrm{BO}_{3}$ при $0.1<x \leq 0.2$ наблюдаются микрокристаллы размером 8-20 $\mu \mathrm{m}$, а количество мелких микрокристаллов намного меньше (рис. $4, f, g, h$ ). При $0.1<x<0.2$, согласно данным рентгенофазового анализа, микрокристаллы $(8-20 \mu \mathrm{m})$ являются двухфазными (табл. 1). Следует отметить, что эти микрокристаллы имеют многочисленные трещины и дефекты (рис. $4, f, g, h$ ).
Таким образом, морфология ортоборатов $\mathrm{Lu}_{0.99-x} \mathrm{Y}_{x} \mathrm{Eu}_{0.01} \mathrm{BO}_{3}$ заметно отличается от морфологии соединений $\mathrm{Lu}_{1-x} \mathrm{Eu}_{x} \mathrm{BO}_{3}$ и $\mathrm{Lu}_{0.99-x} \mathrm{~Tb}_{x} \mathrm{Eu}_{0.01} \mathrm{BO}_{3}$. Образцы $\mathrm{Lu}_{0.99-x} \mathrm{Y}_{x} \mathrm{Eu}_{0.01} \mathrm{BO}_{3}$, имеющие структуру ватерита, состоят преимущественно из микрокристаллов размером 8-20 $\mathrm{m}$, в то время как образцы $\mathrm{Lu}_{1-x} \mathrm{Eu}_{x} \mathrm{BO}_{3} \quad$ и $\mathrm{Lu}_{0.99-x} \mathrm{~Tb}_{x} \mathrm{Eu}_{0.01} \mathrm{BO}_{3}$ со структурой ватерита состоят из микрокристаллов размером $1-2 \mu \mathrm{m}$.

\section{5. Результаты ИК-спектроскопии}

На рис. 5 представлены спектры ИК-поглощения соединений $\quad \mathrm{Lu}_{0.99-x} \mathrm{Eu}_{x} \mathrm{BO}_{3} \quad(0.01 \leq x \leq 0.2)$, $\mathrm{Lu}_{0.99-x} \mathrm{~Tb}_{x} \mathrm{Eu}_{0.01} \mathrm{BO}_{3} \quad(0.07 \leq x \leq 0.2) \quad$ и $\mathrm{Lu}_{0.99-x} \mathrm{Y}_{x} \mathrm{Eu}_{0.01} \mathrm{BO}_{3}(0.1 \leq x \leq 0.25)$ [23,31,32]. В спектрах ортоборатов $\mathrm{Lu}_{0.99} \mathrm{Eu}_{0.01} \mathrm{BO}_{3}, \mathrm{Lu}_{0.92} \mathrm{~Tb}_{0.07} \mathrm{Eu}_{0.01} \mathrm{BO}_{3}$ и $\mathrm{Lu}_{0.89} \mathrm{Y}_{0.10} \mathrm{Eu}_{0.01} \mathrm{BO}_{3}$ (рис. 5, спектры 1,4 и 7), которые по данным рентгенофазового анализа имеют структуру кальцита и являются однофазными (табл. 1), наблюдаются полосы ИК-поглощения вблизи 1230, 770,740 и $630 \mathrm{~cm}^{-1}$, обусловленные колебанием связи $\mathrm{B}-\mathrm{O}$ в структуре с тригональной координацией атомов бора, характерной для фазы кальцита [23,31,32]. Образцы $\quad \mathrm{Lu}_{0.8} \mathrm{Eu}_{0.2} \mathrm{BO}_{3}, \quad \mathrm{Lu}_{0.79} \mathrm{~Tb}_{0.2} \mathrm{Eu}_{0.01} \mathrm{BO}_{3} \quad$ и $\mathrm{Lu}_{0.74} \mathrm{Y}_{0.25} \mathrm{Eu}_{0.01} \mathrm{BO}_{3}$ имеют структуру ватерита (табл. 1 ). ИК-спектры этих образцов (рис. 5, спектры 3, 6 и 9) содержат полосы поглощения вблизи 570, 720, 880, 940, 1040 и $1100 \mathrm{~cm}^{-1}$, характерные для образцов со структурой ватерита, в которой атомы бора имеют тетраэдрическую координацию атомов $[3,23,31,32]$.

В этих спектрах полосы поглощения также обусловлены колебаниями связей В-О. Они неоднократно наблюдались в спектрах ортоборатов различных редких земель (Gd, Er, Dy, Ho, Yb, Y) со структурой ватерита [33-35]. ИК-спектры ортоборатов $\mathrm{Lu}_{0.85} \mathrm{Eu}_{0.15} \mathrm{BO}_{3}$, $\mathrm{Lu}_{0.87} \mathrm{~Tb}_{0.12} \mathrm{Eu}_{0.01} \mathrm{BO}_{3} \quad$ и $\quad \mathrm{Lu}_{0.84} \mathrm{Y}_{0.15} \mathrm{Eu}_{0.01} \mathrm{BO}_{3} \quad$ соответствуют двухфазному состоянию этих соединений и включают полосы поглощения кальцита $(c)$ и ватерита $(v)$ (рис. 5, спектры 2,5 и 8). Как было установлено рентгенофазовым анализом, соотношение фаз кальцит/ватерит в этих образцах составляет 4/96, 72/28 и $80 / 20 \%$, соответственно (табл. 1 ). Такие соотношения фаз хорошо коррелируют с соотношением интенсивностей соответствующих полос поглощения фаз $(c)$ и $(v)$ в ИК-спектрах (рис. 5, спектры 2, 5 и 8).

\section{6. Спектры люминесценции и спектры возбуждения люминесценции}

В спектрах люминесценции ионов $\mathrm{Eu}^{3+}$ в образцах $\mathrm{LuBO}_{3}(\mathrm{Eu})$, имеющих структуру кальцита, наблюдаются две узкие полосы с $\lambda_{\max }=589.8$ и $595.7 \mathrm{~nm}$ (электронный переход ${ }^{5} D_{0} \rightarrow{ }^{7} F_{1}$ ) $\quad[2,22,23]$. Спектр люминесценции ионов $\mathrm{Eu}^{3+}$ в ватеритной модификации $\mathrm{REBO}_{3}(\mathrm{Eu})$, где $\mathrm{RE}(\mathrm{Lu}, \mathrm{Tb}, \mathrm{Y}, \mathrm{Gd})$ содержит три полосы: в области длин волн 588-596 nm (электронный 

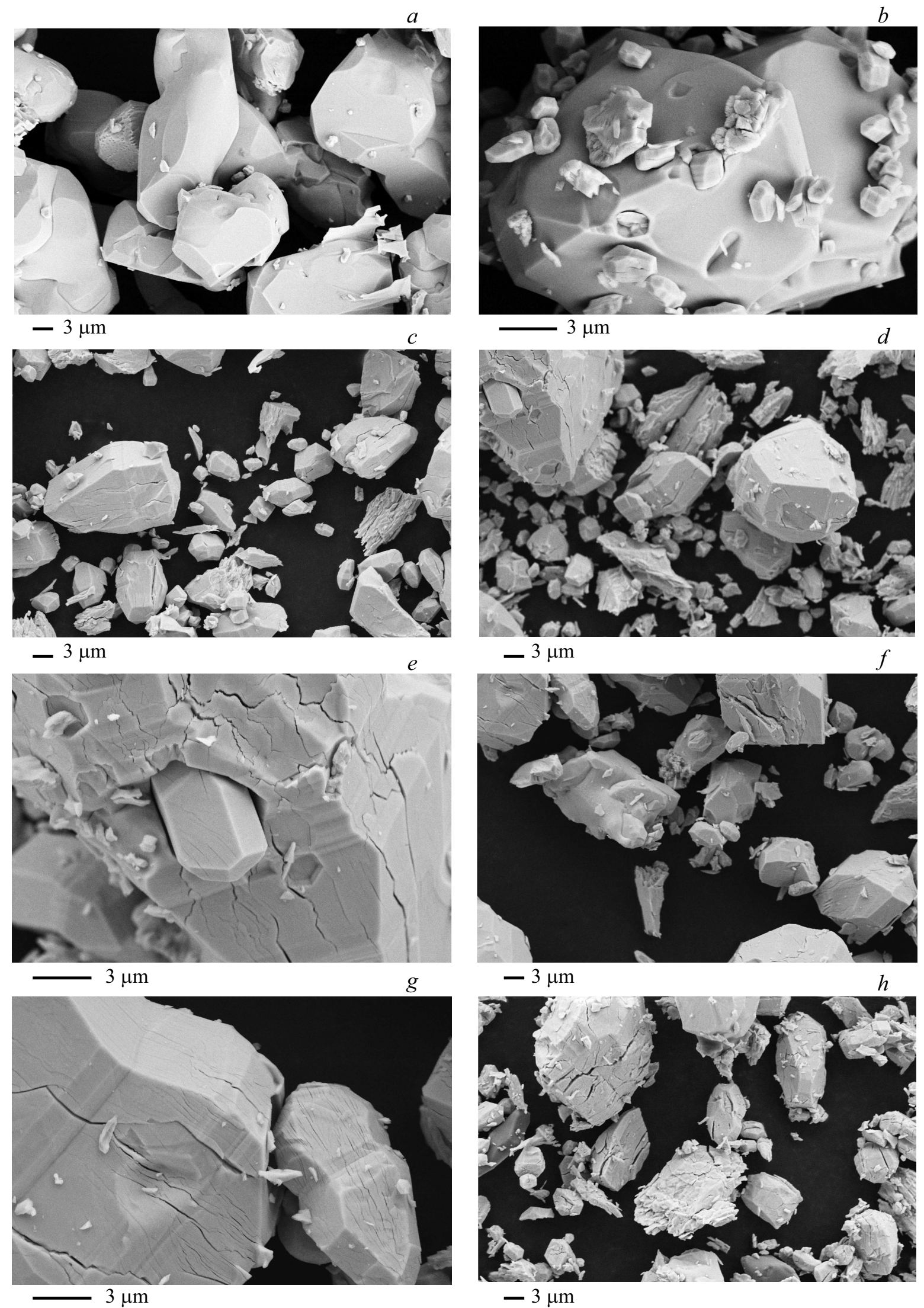

Рис. 4. Морфология образцов $\mathrm{Lu}_{0.99-x} \mathrm{Y}_{x} \mathrm{Eu}_{0.01} \mathrm{BO}_{3} . a-\mathrm{Lu}_{0.89} \mathrm{Y}_{0.1} \mathrm{Eu}_{0.01} \mathrm{BO}_{3} ; b-\mathrm{Lu}_{0.84} \mathrm{Y}_{0.15} \mathrm{Eu}_{0.01} \mathrm{BO}_{3} ; c-\mathrm{Lu}_{0.79} \mathrm{Y}_{0.2} \mathrm{Eu}_{0.01} \mathrm{BO}_{3}$; $d-\mathrm{Lu}_{0.74} \mathrm{Y}_{0.25} \mathrm{Eu}_{0.01} \mathrm{BO}_{3} ; e-\mathrm{Lu}_{0.74} \mathrm{Y}_{0.25} \mathrm{Eu}_{0.01} \mathrm{BO}_{3} ; f-{ }^{*} \mathrm{Lu}_{0.84} \mathrm{Y}_{0.15} \mathrm{Eu}_{0.01} \mathrm{BO}_{3} ; g-{ }^{*} \mathrm{Lu}_{0.84} \mathrm{Y}_{0.15} \mathrm{Eu}_{0.01} \mathrm{BO}_{3} ; h-{ }^{*} \mathrm{Lu}_{0.79} \mathrm{Y}_{0.2} \mathrm{Eu}_{0.01} \mathrm{BO}_{3} ;$ ( $f, g$ и $h-$ образцы, подвергнутые прессованию перед отжигом). 


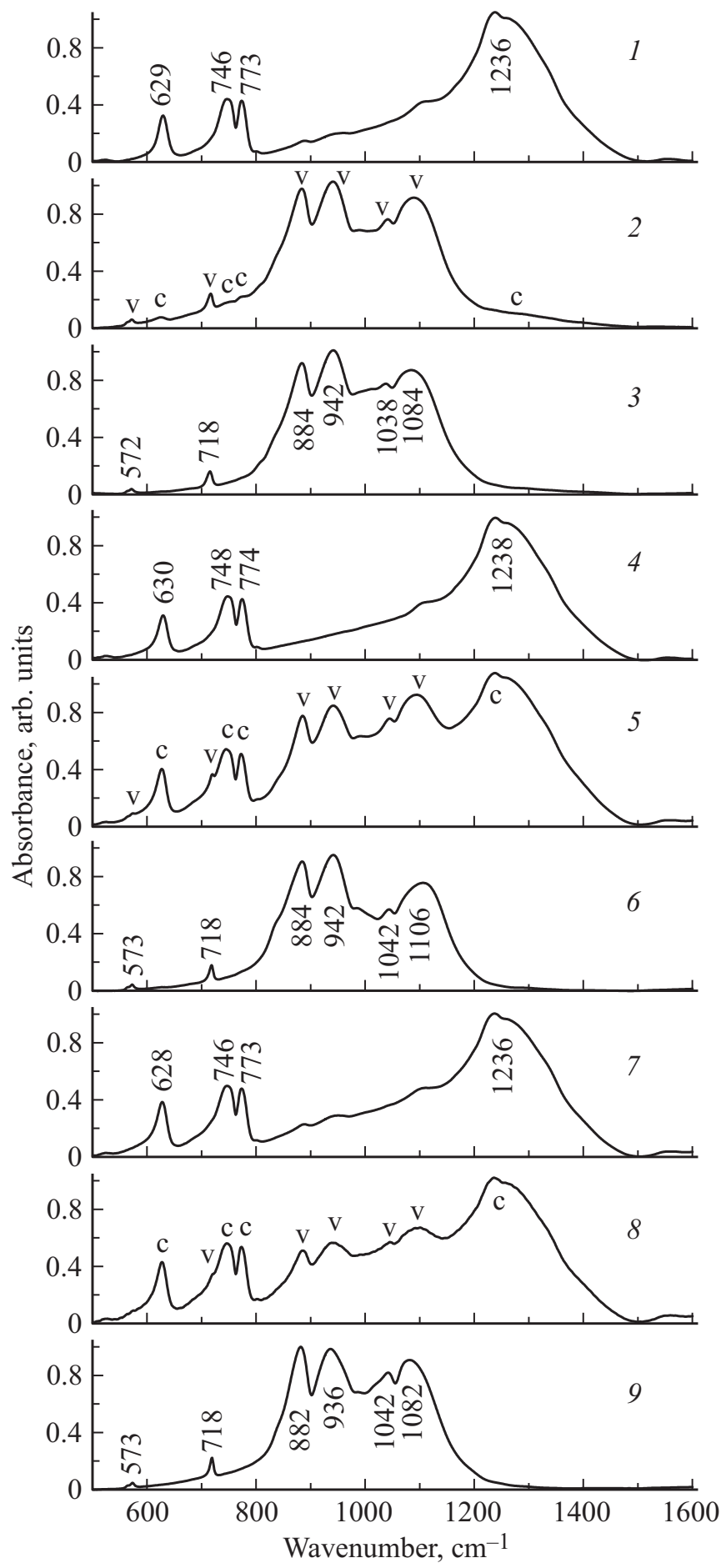

Рис. 5. Спектры ИК-поглощения ортоборатов 1 $\mathrm{Lu}_{0.99} \mathrm{Eu}_{0.01} \mathrm{BO}_{3} ; 2-\mathrm{Lu}_{0.8} \mathrm{Eu}_{0.2} \mathrm{BO}_{3} ; 3-\mathrm{Lu}_{0.85} \mathrm{Eu}_{0.15} \mathrm{BO}_{3}$; $4-\mathrm{Lu}_{0.92} \mathrm{~Tb}_{0.07} \mathrm{Eu}_{0.01} \mathrm{BO}_{3} ; 5-\mathrm{Lu}_{0.79} \mathrm{~Tb}_{0.2} \mathrm{Eu}_{0.01} \mathrm{BO}_{3}$; $6-\mathrm{Lu}_{0.87} \mathrm{~Tb}_{0.12} \mathrm{Eu}_{0.01} \mathrm{BO}_{3} ; 7-\mathrm{Lu}_{0.89} \mathrm{Y}_{0.10} \mathrm{Eu}_{0.01} \mathrm{BO}_{3} ; 8-$ $\mathrm{Lu}_{0.74} \mathrm{Y}_{0.25} \mathrm{Eu}_{0.01} \mathrm{BO}_{3} ; 9-\mathrm{Lu}_{0.84} \mathrm{Y}_{0.15} \mathrm{Eu}_{0.01} \mathrm{BO}_{3}$.

переход $\left.\quad{ }^{5} D_{0} \rightarrow{ }^{7} F_{1}\right), \quad 608-613 \quad$ и $\quad 624-632 \mathrm{~nm}$ $\left({ }^{5} D_{0} \rightarrow{ }^{7} F_{2}\right) \quad[2-4,22]$. Согласно данным рентгенофазового анализа, ортобораты $\mathrm{Lu}_{1-x} \mathrm{Eu}_{x} \mathrm{BO}_{3}$ при $0 \leq x \leq 0.07, \mathrm{Lu}_{0.99-x} \mathrm{~Tb}_{x} \mathrm{Eu}_{0.01} \mathrm{BO}_{3}$ при $0 \leq x \leq 0.09$ и
$\mathrm{Lu}_{0.99-x} \mathrm{Y}_{x} \mathrm{Eu}_{0.01} \mathrm{BO}_{3}$ при $0 \leq x \leq 0.1$, имеют структуру кальцита. Структуру ватерита соединения $\mathrm{Lu}_{1-x} \mathrm{Eu}_{x} \mathrm{BO}_{3}$ и $\mathrm{Lu}_{0.99-x} \mathrm{~Tb}_{x} \mathrm{Eu}_{0.01} \mathrm{BO}_{3}$ имеют при $x \geq 0.2, \quad \mathrm{a}$ $\mathrm{Lu}_{0.99-x} \mathrm{Y}_{x} \mathrm{Eu}_{0.01} \mathrm{BO}_{3}$ - при $x \geq 0.25$ (табл. 1).

$\mathrm{B}$ настоящей работе в образцах бората лютеция, легированного $\mathrm{Tb}$ и $\mathrm{Y}$, в качестве оптически активных и структурно чувствительных меток использовались ионы $\mathrm{Eu}^{3+}$ в количестве 1 at.\%.

\section{1. Спектры возбуждения люминесценции ортоборатов}

Спектр возбуждения наиболее интенсивной полосы свечения ионов $\mathrm{Eu}^{3+}$ в кальцитной модификации $\mathrm{Lu}_{1-x} \mathrm{Eu}_{x} \mathrm{BO}_{3} \quad\left(\lambda_{\max }=589.8 \mathrm{~nm}\right)$ бората лютеция при $x=0.07$ представлен на рис. 6 , спектр 1 . Аналогичные спектры наблюдаются для образцов $\mathrm{Lu}_{1-x} \mathrm{Eu}_{x} \mathrm{BO}_{3}$ при $0 \leq x \leq 0.07$. Спектры возбуждения люминесценции полос с $\lambda_{\max }=589.8$ и $595.7 \mathrm{~nm}$ совпадают. В спектрах возбуждения люминесценции (СВЛ), полученных при $970^{\circ} \mathrm{C}$ образцов $\mathrm{Lu}_{1-x} \mathrm{Eu}_{x} \mathrm{BO}_{3}$ при $0 \leq x \leq 0.07$, наблюдается широкая коротковолновая полоса в области длин волн $220-290 \mathrm{~nm}\left(\lambda_{\mathrm{ex}} \sim 260 \mathrm{~nm}\right)$ (полоса с переносом заряда - ППЗ) и ряд узких полос в области длин волн 290-500 nm (рис. 6, спектр 1). Наиболее интенсивной в этой области спектра является полоса, соответствующая резонансному возбуждению ионов $\mathrm{Eu}^{3+}\left(\lambda_{\mathrm{ex}}=394 \mathrm{~nm}\right.$ $\left.\left({ }^{7} F_{0} \rightarrow{ }^{5} L_{6}\right)\right)$. Интенсивность полосы с переносом заряда в $\sim 10$ раз превосходит интенсивность полосы с $\lambda_{\mathrm{ex}}=394 \mathrm{~nm}$. Наличие доминирующей коротковолновой полосы является важной особенностью СВЛ образцов, имеющих структуру кальцита. Иная ситуация наблюдается в образцах $\mathrm{Lu}_{1-x} \mathrm{Eu}_{x} \mathrm{BO}_{3}$ со структурой ватерита.

СВЛ наиболее интенсивной полосы свечения ионов $\mathrm{Eu}^{3+}\left(\lambda_{\max }=593.3 \mathrm{~nm}\right)$ в борате лютеция, легированном 20 at.\% Eu, имеющего структуру ватерита (табл. 1), также содержит широкую коротковолновую полосу (ППЗ) с максимумом $\sim 247 \mathrm{~nm}$ и ряд узких резонансных полос, наиболее интенсивная из которых находится при $\lambda_{\mathrm{ex}}=394 \mathrm{~nm}$, а также наблюдаются полосы $\sim 467$ и $469 \mathrm{~nm}\left({ }^{7} F_{0} \rightarrow{ }^{5} D_{2}\right)$ (рис. 6, спектр 2). В образцах, содержащих 20 at.\% Eu, интенсивность резонансной полосы $394 \mathrm{~nm}$ в $\sim 1.6$ раза больше интенсивности полосы с переносом заряда.

Спектры возбуждения люминесценции основных полос свечения ортоборатов $\mathrm{Lu}_{0.99-x} \mathrm{Y}_{x} \mathrm{Eu}_{0.01} \mathrm{BO}_{3}$ подобны СВЛ соединений $\mathrm{Lu}_{1-x} \mathrm{Eu}_{x} \mathrm{BO}_{3}$ (рис. 6, спектры 3,4). В спектрах возбуждения люминесценции наиболее интенсивной полосы свечения кальцитной модификации образцов $\mathrm{Lu}_{0.89} \mathrm{Y}_{0.1} \mathrm{Eu}_{0.01} \mathrm{BO}_{3}\left(\lambda_{\max }=589.8 \mathrm{~nm}\right)$ наибольшую интенсивность имеет ультрафиолетовая полоса (полоса с переносом заряда (ППЗ)) $250 \mathrm{~nm}$ (рис. 6, спектр 3). Интенсивность резонансной полосы, соответствующей возбуждению $\mathrm{Eu}^{3+}$-ионов $(394 \mathrm{~nm})$ более чем в 30 раз меньше интенсивности ППЗ. Спектр возбуждения люминесценции полосы с $\lambda_{\max }=593.3 \mathrm{~nm}$ образцов $\mathrm{Lu}_{0.74} \mathrm{Y}_{0.25} \mathrm{Eu}_{0.01} \mathrm{BO}_{3}$, имеющих структуру ватерита 
(табл. 1), содержит широкую коротковолновую полосу (ППЗ) с максимумом $\sim 243 \mathrm{~nm}$ и ряд узких резонансных полос, наиболее интенсивная из которых находится при $394 \mathrm{~nm}$ (рис. 6, спектр 4). Важно отметить, что в ватеритной модификации бората лютеция, легированного 25 at.\% Y, интенсивность ППЗ всего лишь в 1.2 раза интенсивнее резонансной полосы возбуждения ионов $\mathrm{Eu}^{3+}(394 \mathrm{~nm})$.

При возбуждении люминесценции ионов $\mathrm{Eu}^{3+}$ светом, соответствующим области интенсивного поглощения образца (в полосе с переносом заряда), мы получаем информацию о ближайшем окружении ионов $\mathrm{Eu}^{3+}$ в приповерхностном слое микрокристаллов образца. При возбуждении образца в области прозрачности $(\lambda=300-500 \mathrm{~nm})$ мы получаем информацию о ближайшем окружении ионов $\mathrm{Eu}^{3+}$ в объеме микрокристаллов образца.

В спектре возбуждения люминесценции (СВЛ) наиболее интенсивной полосы свечения ионов $\mathrm{Eu}^{3+}$ кальцитной модификации ортобората $\mathrm{Lu}_{0.92} \mathrm{~Tb}_{0.07} \mathrm{Eu}_{0.01} \mathrm{BO}_{3}$ $\left(\lambda_{\max }=589.8 \mathrm{~nm}\right)$ наблюдаются широкая полоса в диапазоне длин волн 220-290 nm (полоса с переносом заряда), узкая полоса с $\lambda_{\mathrm{ex}}=378 \mathrm{~nm}$ и очень слабая резонансная полоса возбуждения ионов $\mathrm{Eu}^{3+}$ $\lambda_{\mathrm{ex}}=394 \mathrm{~nm}$ (рис. 6, спектр 5). Следует отметить, что полоса $378 \mathrm{~nm}$ наблюдается в СВЛ наиболее интенсивной полосы люминесценции ионов $\mathrm{Tb}^{3+}$ в образцах $\mathrm{Lu}_{0.95} \mathrm{~Tb}_{0.05} \mathrm{BO}_{3}$, имеющих структуру кальцита $\left(\lambda_{\max }=541.8 \mathrm{~nm}\left({ }^{5} D_{4} \rightarrow{ }^{7} F_{5}\right)\right)$. Кроме полосы $378 \mathrm{~nm} \mathrm{в}$ СВЛ ионов $\mathrm{Tb}^{3+}$ наблюдаются еще четыре полосы в коротковолновой области спектра с $\lambda_{\mathrm{ex}}=235.7,260.2$, 273.5 и $284.3 \mathrm{~nm}$ (переход $4 f^{8} \rightarrow 4 f^{7} 5 d^{1}$ ) $[3,4,23]$.

Важно отметить, что при возбуждении ионов $\mathrm{Tb}^{3+}$ в образцах $\mathrm{Lu}_{0.92} \mathrm{~Tb}_{0.07} \mathrm{Eu}_{0.01} \mathrm{BO}_{3} \quad\left(\lambda_{\mathrm{ex}}=378 \mathrm{~nm}\right.$ $\left.\left({ }^{7} F_{6} \rightarrow{ }^{5} D_{3}\right)\right)$ наблюдается свечение ионов $\mathrm{Eu}^{3+}$, это однозначно свидетельствует о переносе энергии от ионов $\mathrm{Tb}^{3+}$ к ионам $\mathrm{Eu}^{3+}$. Коротковолновые полосы, наблюдающиеся в СВЛ ионов $\mathrm{Tb}^{3+}$, проявляются в виде слабых особенностей на полосе с переносом заряда в СВЛ ионов $\mathrm{Eu}^{3+}$ (рис. 6, спектр 5). Интенсивность резонансной полосы возбуждения свечения ионов $\mathrm{Eu}^{3+}$ $\left(\lambda_{\mathrm{ex}}=394 \mathrm{~nm}\right)$ в $\sim 40$ раз слабее ППЗ, в то время как интенсивность полосы $378 \mathrm{~nm}$ в $\sim 10$ раз меньше интенсивности ППЗ.

Спектр возбуждения люминесценции наиболее интенсивной полосы свечения ионов $\mathrm{Eu}^{3+}$ ватеритной модификации ортобората $\mathrm{Lu}_{0.79} \mathrm{~Tb}_{0.2} \mathrm{Eu}_{0.01} \mathrm{BO}_{3}$ $\left(\lambda_{\max }=593.3 \mathrm{~nm}\right)$ приведен на рис. 6 , спектр 6. В СВЛ наблюдается две широкие коротковолновые полосы с $\lambda_{\mathrm{ex}}=242$ и $285 \mathrm{~nm}$ и целый ряд узких полос в диапазоне длин волн $360-390 \mathrm{~nm}$, самой интенсивной из которых является полоса $378 \mathrm{~nm}$. Кроме того, в СВЛ $\mathrm{Lu}_{0.79} \mathrm{~Tb}_{0.2} \mathrm{Eu}_{0.01} \mathrm{BO}_{3}$ наблюдается резонансная полоса возбуждения свечения ионов $\mathrm{Eu}^{3+}$ $\left(\lambda_{\mathrm{ex}}=394 \mathrm{~nm}\right)$, а также полосы $467,469 \mathrm{~nm}\left({ }^{7} F_{0} \rightarrow{ }^{5} D_{2}\right)$ и $489 \mathrm{~nm}$. В спектре возбуждения наиболее интенсивной полосы люминесценции ионов $\mathrm{Tb}^{3+}$ в об-

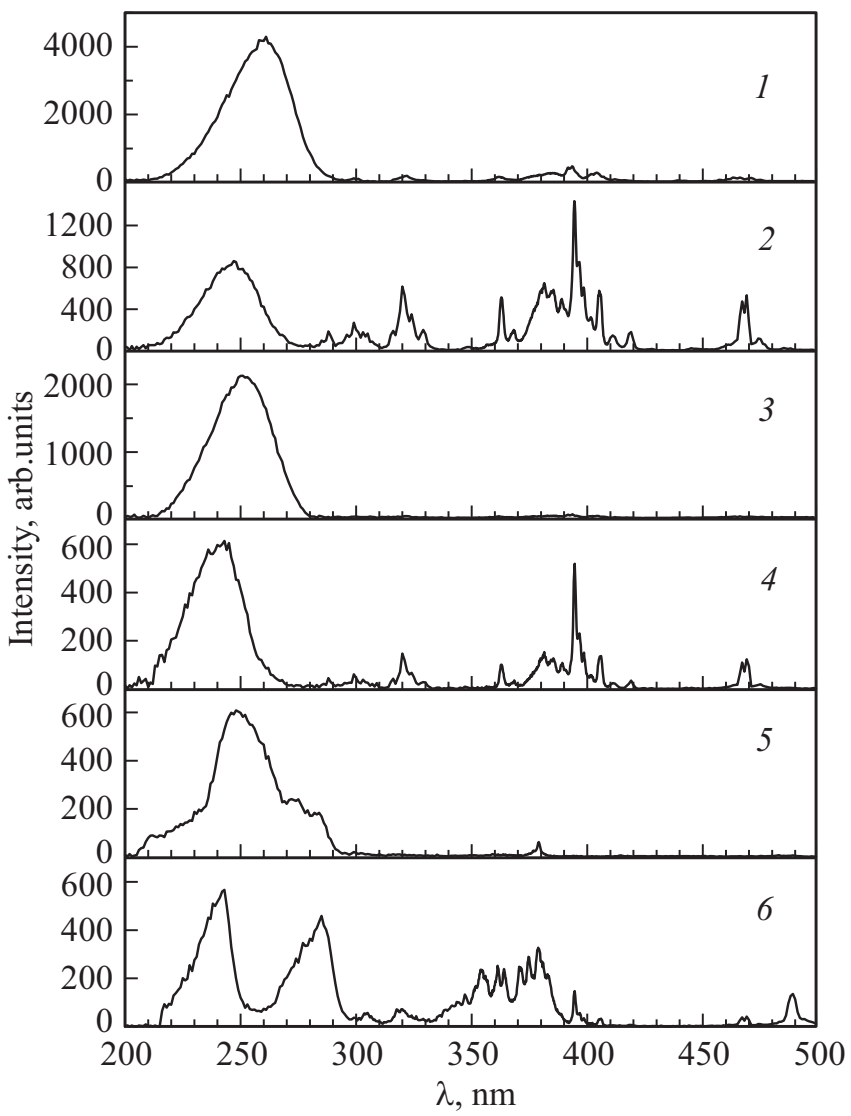

Pис. 6. Спектры возбуждения люминесценции ортоборатов. $1-\mathrm{Lu}_{0.93} \mathrm{Eu}_{0.07} \mathrm{BO}_{3} ; 2-\mathrm{Lu}_{0.8} \mathrm{Eu}_{0.2} \mathrm{BO}_{3} ; 3-$ $\mathrm{Lu}_{0.89} \mathrm{Y}_{0.1} \mathrm{Eu}_{0.01} \mathrm{BO}_{3} ; 4-\mathrm{Lu}_{0.74} \mathrm{Y}_{0.25} \mathrm{Eu}_{0.01} \mathrm{BO}_{3} ; 5-$ $\mathrm{Lu}_{0.92} \mathrm{~Tb}_{0.07} \mathrm{Eu}_{0.01} \mathrm{BO}_{3} ; 6-\mathrm{Lu}_{0.79} \mathrm{~Tb}_{0.2} \mathrm{Eu}_{0.01} \mathrm{BO}_{3} ; \quad(1,3,5-$ $\lambda_{\max }=589.8 \mathrm{~nm} ; 2,4,6-\lambda_{\max }=593.3 \mathrm{~nm}$ ).

разцах $\mathrm{Lu}_{0.8} \mathrm{~Tb}_{0.2} \mathrm{BO}_{3}$, имеющих структуру ватерита $\left(\lambda_{\max }=542.3 \mathrm{~nm} \quad\left({ }^{5} D_{4} \rightarrow{ }^{7} F_{5}\right)\right)$, наблюдаются полосы 242 и $285 \mathrm{~nm}$ (переход $4 f^{8} \rightarrow 4 f^{7} 5 d^{1}$ ), узкие полосы в области $360-390 \mathrm{~nm}$, полосы 378 и $489 \mathrm{~nm}$ $\left({ }^{7} F_{6} \rightarrow{ }^{5} D_{4}\right)[3,4,23]$. Таким образом, также, как и в кальцитной модификации, в ватеритной структуре ортоборатов $\mathrm{Lu}_{0.79} \mathrm{~Tb}_{0.2} \mathrm{Eu}_{0.01} \mathrm{BO}_{3}$ свечение ионов $\mathrm{Eu}^{3+}$ наблюдается при возбуждении ионов $\mathrm{Tb}^{3+}\left(\lambda_{\mathrm{ex}}=242\right.$, 285, 378 и $489 \mathrm{~nm})$, что свидетельствует о переносе энергии от ионов $\mathrm{Tb}^{3+}$ к ионам $\mathrm{Eu}^{3+}$. Для кальцитной и ватеритной модификаций $\mathrm{Lu}_{0.99-x} \mathrm{~Tb}_{x} \mathrm{Eu}_{0.01} \mathrm{BO}_{3}$ интенсивность свечения ионов $\mathrm{Eu}^{3+}$ при возбуждении светом с $\lambda_{\mathrm{ex}}=378 \mathrm{~nm}$ в несколько раз выше, чем при резонансном возбуждении $\mathrm{Eu}^{3+}\left(\lambda_{\mathrm{ex}}=394 \mathrm{~nm}\right)$. Поэтому для получения информации о ближайшем окружении ионов $\mathrm{Eu}^{3+}$, находящихся в объеме этих образцов, исследование спектров люминесценции ионов $\mathrm{Eu}^{3+}$ будет проводиться при $\lambda_{\mathrm{ex}}=378 \mathrm{~nm}$.

Следует отметить, что интенсивность полосы $242 \mathrm{~nm}$ $\left(I_{242}\right)$ в СВЛ ионов $\mathrm{Tb}^{3+}$ в образцах $\mathrm{Lu}_{0.8} \mathrm{~Tb}_{0.2} \mathrm{BO}_{3}$ в 1.3 раза меньше интенсивности полосы $285 \mathrm{~nm}$ $\left(I_{285}\right)[23]$. В то же время, $I_{242}$ в СВЛ ионов $\mathrm{Eu}^{3+}$ в образ- 

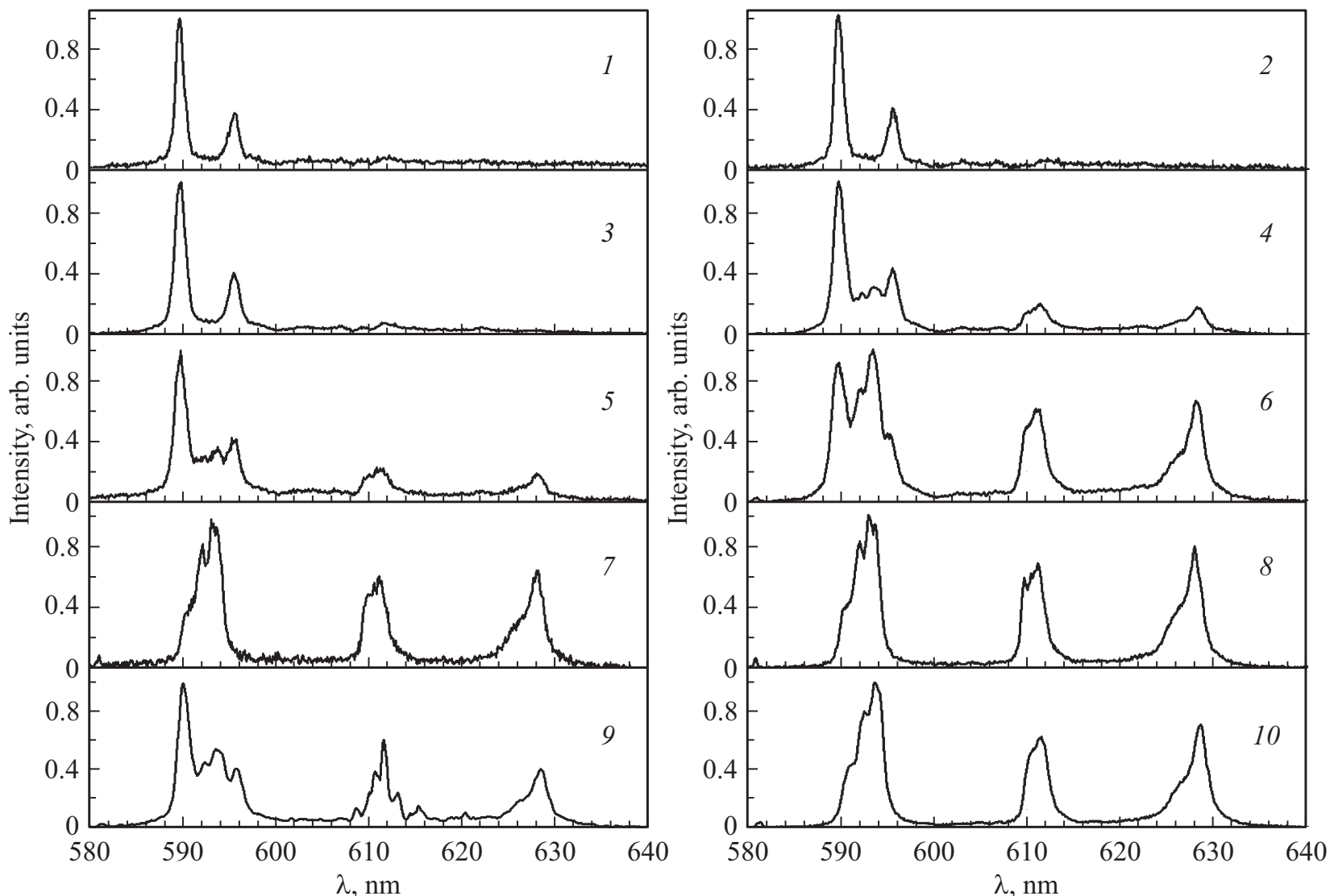

Рис. 7. Спектры люминесценции ортоборатов $\mathrm{Lu}_{1-x} \mathrm{Eu}_{x} \mathrm{BO}_{3} .1,2-\mathrm{Lu}_{0.93} \mathrm{Eu}_{0.07} \mathrm{BO}_{3} ; 3,4-\mathrm{Lu}_{0.91} \mathrm{Eu}_{0.09} \mathrm{BO}_{3} ; \quad 5,6-$ $\mathrm{Lu}_{0.885} \mathrm{Eu}_{0.115} \mathrm{BO}_{3} ; 7,8-\mathrm{Lu}_{0.8} \mathrm{Eu}_{0.2} \mathrm{BO}_{3} ; 9,10-{ }^{*} \mathrm{Lu}_{0.85} \mathrm{Eu}_{0.15} \mathrm{BO}_{3} ;\left(1-\lambda_{\text {ex }}=260 \mathrm{~nm}, 3\right.$ и $9-\lambda_{\text {ex }}=250 \mathrm{~nm} ; 5$ и $7-\lambda_{\text {ex }}=245 \mathrm{~nm} ;$ 2, 4, 6, 8 и $\left.10-\lambda_{\mathrm{ex}}=394 \mathrm{~nm}\right) .{ }^{*} \mathrm{Lu}_{0.85} \mathrm{Eu}_{0.15} \mathrm{BO}_{3}$ - образец, подвергнутый прессованию перед отжигом.

цах $\mathrm{Lu}_{0.79} \mathrm{~Tb}_{0.2} \mathrm{Eu}_{0.01} \mathrm{BO}_{3}$ в 1.24 раза больше $I_{285}$ (рис. 6, спектр 6). Усиление интенсивности полосы $242 \mathrm{~nm} \mathrm{в}$ 1.6 раза в образцах $\mathrm{Lu}_{0.79} \mathrm{~Tb}_{0.2} \mathrm{Eu}_{0.01} \mathrm{BO}_{3}$ обусловлено, скорее всего тем, что в этих образцах на полосу $242 \mathrm{~nm}$ накладывается полоса с переносом заряда, находящаяся в том же интервале длин волн.

На основании исследований спектров возбуждения свечения ионов $\mathrm{Eu}^{3+}$ в образцах $\mathrm{Lu}_{0.99-x} \mathrm{~Tb}_{x} \mathrm{Eu}_{0.01} \mathrm{BO}_{3}$ можно сделать следующий вывод. Информацию о ближайшем окружении ионов $\mathrm{Eu}^{3+}$ в приповерхностном слое и объеме образца можно получить при возбуждении свечения ионов $\mathrm{Eu}^{3+}$ светом с $\lambda_{\mathrm{ex}}=250-240$ и $378 \mathrm{~nm}$ соответственно.

\section{2. Спектры люминесценции ортоборатов $\mathrm{Lu}_{1-x} \mathrm{Eu}_{x} \mathrm{BO}_{3}$ и $\mathrm{Lu}_{0.99-x} \mathrm{~Tb}_{x} \mathrm{Eu}_{0.01} \mathrm{BO}_{3}$}

Спектры люминесценции (СЛ) соединений $\mathrm{Lu}_{1-x} \mathrm{Eu}_{x} \mathrm{BO}_{3}(x=0.07,0.09,0.115,0.15$ и 0.2$)$ при возбуждении светом $\left(\lambda_{\mathrm{ex}}=394 \mathrm{~nm}\right)$, соответствующим резонансному возбуждению ионов $\mathrm{Eu}^{3+}$, и в максимуме полосы с переносом заряда $\left(\lambda_{\mathrm{ex}} \sim 260-245 \mathrm{~nm}\right)$, представлены на рис. 7. Спектры люминесценции образцов $\mathrm{Lu}_{1-x} \mathrm{Eu}_{x} \mathrm{BO}_{3}$ при $0 \leq x \leq 0.07$, имеющих, согласно данным рентгенофазового анализа структуру кальцита (табл. 1), идентичны. В этих образцах спектры люминесценции приповерхностного слоя $\left(\lambda_{\mathrm{ex}}=260 \mathrm{~nm}\right)$, и объема образца $\left(\lambda_{\mathrm{ex}}=394 \mathrm{~nm}\right)$ совпадают (рис. 7 , спектры 1 и 2). Они содержат полосы с $\lambda_{\max }=589.8$ и $595.7 \mathrm{~nm}$, характерные для кальцитной модификации $\mathrm{LuBO}_{3}(\mathrm{Eu})[2,22,23]$. В образцах $\mathrm{Lu}_{0.91} \mathrm{Eu}_{0.09} \mathrm{BO}_{3}$ спектр люминесценции приповерхностного слоя $\left(\lambda_{\mathrm{ex}}=250 \mathrm{~nm}\right)$ содержит полосы с $\lambda_{\max }=589.8$ и $595.7 \mathrm{~nm}$, характерные для кальцитной модификации $\mathrm{Lu}_{1-x} \mathrm{Eu}_{x} \mathrm{BO}_{3}$ (рис. 7, спектр 3). В то же время, спектр люминесценции объема образца $\left(\lambda_{\mathrm{ex}}=394 \mathrm{~nm}\right)$ содержит как полосы, характерные для кальцитной модификации, так и полосы, соответствующие ватеритной структуре этих микрокристаллов (рис. 7, спектр 4). В образцах $\mathrm{Lu}_{0.91} \mathrm{Eu}_{0.09} \mathrm{BO}_{3}$, содержащих $13.5 \%$ ватерита (табл. 1), количество мелких микрокристаллов размером $1-2 \mu \mathrm{m}$, имеющих структуру ватерита, составляет всего $\sim 0.4 \%$ (раздел 4.1 , рис. $3, b$ ). Поэтому значительная доля ватеритной фазы $\mathrm{Lu}_{0.91} \mathrm{Eu}_{0.09} \mathrm{BO}_{3}$ содержится в микрокристаллах размером $15-20 \mu \mathrm{m}$. Возникновение в спектре люминесценции при резонансном возбуждении свечения ионов $\mathrm{Eu}^{3+}\left(\lambda_{\mathrm{ex}}=394 \mathrm{~nm}\right)$ полос, 588-596, 608-613 и 624-632 nm свидетельствует о том, что 

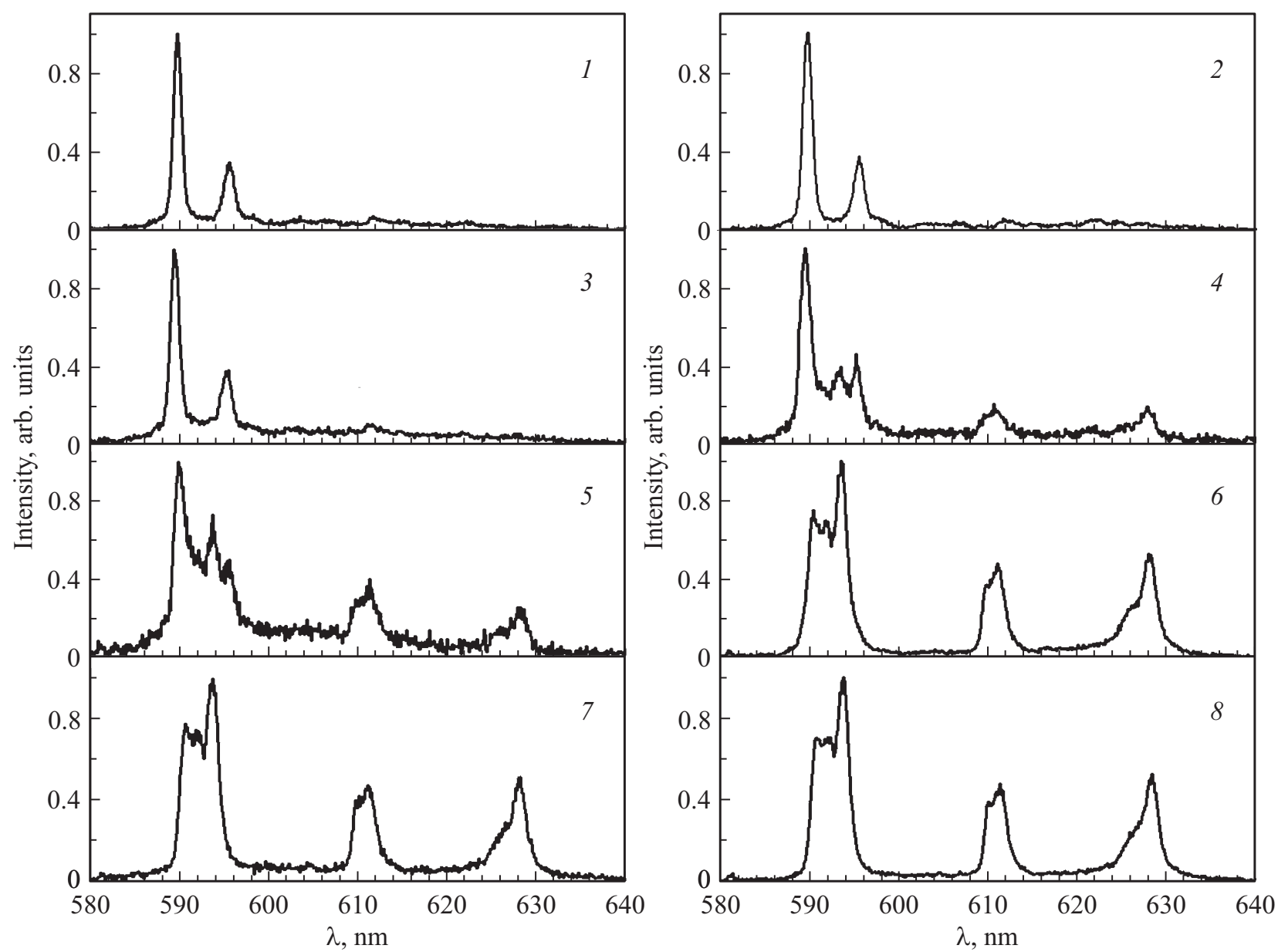

Рис. 8. Спектры люминесценции ортоборатов $\mathrm{Lu}_{0.99-x} \mathrm{~Tb}_{x} \mathrm{Eu}_{0.01} \mathrm{BO}_{3} .1,2-\mathrm{Lu}_{0.92} \mathrm{~Tb}_{0.07} \mathrm{Eu}_{0.01} \mathrm{BO}_{3} ; 3,4-\mathrm{Lu}_{0.885} \mathrm{~Tb}_{0.105} \mathrm{Eu}_{0.01} \mathrm{BO}_{3}$; $5,6-\mathrm{Lu}_{0.84} \mathrm{~Tb}_{0.15} \mathrm{Eu}_{0.01} \mathrm{BO}_{3} ; 7,8-\mathrm{Lu}_{0.79} \mathrm{~Tb}_{0.2} \mathrm{Eu}_{0.01} \mathrm{BO}_{3}:\left(1,3\right.$ и $5-\lambda_{\text {ех }}=250 \mathrm{~nm} ; 7-\lambda_{\text {ех }}=245 \mathrm{~nm} ; 2,4,6$ и $\left.8-\lambda_{\text {ex }}=378 \mathrm{~nm}\right)$.

ватеритная модификация в этих образцах формируется в объеме крупных микрокристаллов размером $15-20 \mu \mathrm{m}$, в то время как их приповерхностный слой все еще имеет структуру кальцита. При дальнейшем увеличении концентрации европия фаза ватерита появляется и в приповерхностном слое микрокристаллов. В образцах $\mathrm{Lu}_{0.885} \mathrm{Eu}_{0.15} \mathrm{BO}_{3}$ спектры люминесценции объема образца и приповерхностного слоя содержат полосы, характерные для фаз кальцита $(589.8$ и $595.7 \mathrm{~nm})$ и ватерита $(588-596,608-613$ и $624-632$ nm) (рис. 7, спектры 5,6). Эти образцы содержат 36\% кальцита и $64 \%$ ватерита. Спектры люминесценции приповерхностного слоя и объема образца $\mathrm{Lu}_{0.8} \mathrm{Eu}_{0.2} \mathrm{BO}_{3}$ содержат только полосы, характерные для ватеритной модификации $\mathrm{LuBO}_{3}(\mathrm{Eu})$ (рис. 7, спектры 7, 8). Эти образцы состоят из подавляющего большинства микрокристаллов размером $1-2 \mu \mathrm{m}$. Это свидетельствует о том, что микрокристаллы $(1-2 \mu \mathrm{m})$ ортоборатов $\mathrm{Lu}_{1-x} \mathrm{Eu}_{x} \mathrm{BO}_{3}$ имеют структуру ватерита, также, как и микрокристаллы $\mathrm{Lu}_{0.99-x} \mathrm{Gd}_{x} \mathrm{Eu}_{0.01} \mathrm{BO}_{3}$ размером 1-2 $\mu \mathrm{m}$ [18].

Важно отметить, что вывод о том, что образование фазы ватерита происходит в объеме микрокристаллов, имеющих структуру кальцита, подтверждается результатами исследования ортоборатов ${ }^{*} \mathrm{Lu}_{0.85} \mathrm{Eu}_{0.15} \mathrm{BO}_{3}$, подвергнутых прессованию перед отжигом. Средний размер микрокристаллов этих образцов составляет $8-15 \mu \mathrm{m}$, а количество мелких микрокристаллов $(1-2 \mu \mathrm{m})$ крайне мало (рис. 3,e). В спектре люминесценции объема этих образцов, содержащих $25 \%$ фазы кальцита и $75 \%$ фазы ватерита (табл. 1) (рис. 7, спектр 10), наблюдаются только полосы, характерные для фазы ватерита $\mathrm{LuBO}_{3}(\mathrm{Eu})$. В то же время в спектре люминесценции приповерхностного слоя содержатся полосы кальцитной и ватеритной модификаций $\mathrm{LuBO}_{3}(\mathrm{Eu})$ (рис. 7, спектр 9).

Спектры люминесценции ортоборатов $\mathrm{Lu}_{0.99-x} \mathrm{~Tb}_{x} \mathrm{Eu}_{0.01} \mathrm{BO}_{3}$ представлены на рис. 8. В этих соединениях изменения спектров люминесценции при увеличении концентрации $\mathrm{Tb}^{3+}$ подобны тем, которые наблюдались в ортоборатах $\mathrm{Lu}_{1-x} \mathrm{Eu}_{x} \mathrm{BO}_{3}$. При $0 \leq x<0.09$ образцы $\mathrm{Lu}_{0.99-x} \mathrm{~Tb}_{x} \mathrm{Eu}_{0.01} \mathrm{BO}_{3}$ являются однофазными и имеют структуру кальцита (табл. 1). Спектры люминесценции этих образцов совпадают. В качестве примера на рис. 8 , спектры 1 и 2 , приведены СЛ приповерхностного слоя $\left(\lambda_{\mathrm{ex}}=250 \mathrm{~nm}\right)$ и объема 
$\left(\lambda_{\text {ex }}=378 \mathrm{~nm}\right) \quad$ образцов $\quad \mathrm{Lu}_{0.92} \mathrm{~Tb}_{0.07} \mathrm{Eu}_{0.01} \mathrm{BO}_{3} . \quad$ Они содержат полосы 589.8 и $595.7 \mathrm{~nm}$, характерные для кальцитной модификации $\mathrm{LuBO}_{3}(\mathrm{Eu})$. Спектр люминесценции приповерхностного слоя $\left(\lambda_{\mathrm{ex}}=250 \mathrm{~nm}\right)$ образцов $\mathrm{Lu}_{0.885} \mathrm{~Tb}_{0.105} \mathrm{Eu}_{0.01} \mathrm{BO}_{3}$ также содержит полосы, соответствующие кальцитной модификации $\mathrm{LuBO}_{3}(\mathrm{Eu})$ (рис. 8, спектр 3), В то же время, при возбуждении объема этих образцов $\left(\lambda_{\text {ex }}=378 \mathrm{~nm}\right)$ наблюдаются как полосы, характерные для кальцитной, так и для ватеритной структур этих образцов (рис. 8, спектр 4). В образцах $\mathrm{Lu}_{0.885} \mathrm{~Tb}_{0.105} \mathrm{Eu}_{0.01} \mathrm{BO}_{3}$, содержащих $21 \%$ ватерита (табл. 1), суммарный объем мелких микрокристаллов размером $1-2 \mu \mathrm{m}$, имеющих структуру ватерита, составляет всего $\sim 2 \%$ (раздел 4.1, рис. $3, g$ ). Поэтому основная доля ватеритной фазы $\mathrm{Lu}_{0.91} \mathrm{Eu}_{0.09} \mathrm{BO}_{3}$ содержится в микрокристаллах размером 15-20 $\mu \mathrm{m}$. Появление в спектре люминесценции объема этих микрокристаллов $\left(\lambda_{\mathrm{ex}}=378 \mathrm{~nm}\right)$ полос, $588-596,608-613$ и $624-632 \mathrm{~nm}$ свидетельствует о том, что ватеритная модификация в крупных микрокристаллах размером $15-20 \mu \mathrm{m}$ в образцах $\mathrm{Lu}_{0.99-x} \mathrm{~Tb}_{x} \mathrm{Eu}_{0.01} \mathrm{BO}_{3}$ формируется в их объеме. При дальнейшем увеличении концентрации $\mathrm{Tb}^{3+}$ фаза ватерита образуется и в приповерхностном слое микрокристаллов. В ортоборатах $\mathrm{Lu}_{0.84} \mathrm{~Tb}_{0.15} \mathrm{Eu}_{0.01} \mathrm{BO}_{3}$, содержащих $86 \%$ ватерита, в объеме образца наблюдаются только полосы, характерные для ватеритной модификации, в то время как спектр люминесценции приповерхностного слоя содержит полосы, характерные как для кальцитной, так и ватеритной структур этих образцов (рис. 8, спектры 5,6). При концентрации ионов $\mathrm{Tb}^{3+} 20$ at.\% в спектре люминесценции объема и приповерхностного слоя наблюдаются полосы, характерные только для ватеритной модификации $\mathrm{Lu}_{0.99-x} \mathrm{~Tb}_{x} \mathrm{Eu}_{0.01} \mathrm{BO}_{3}$ (рис. 8, спектры 7, 8).

\section{3. Спектры люминесценции ортоборатов $\mathrm{Lu}_{0.99-x} \mathrm{Y}_{x} \mathrm{Eu}_{0.01} \mathrm{BO}_{3}$}

Как отмечалось в разделе 4.2, морфология ортоборатов $\mathrm{Lu}_{0.99-x} \mathrm{Y}_{x} \mathrm{Eu}_{0.01} \mathrm{BO}_{3}$ заметно отличается от морфологии соединений $\mathrm{Lu}_{1-x} \mathrm{Eu}_{x} \mathrm{BO}_{3}$ и $\mathrm{Lu}_{0.99-x} \mathrm{~Tb}_{x} \mathrm{Eu}_{0.01} \mathrm{BO}_{3}$. Образцы $\mathrm{Lu}_{0.99-x} \mathrm{Y}_{x} \mathrm{Eu}_{0.01} \mathrm{BO}_{3}$ в исследованном диапазоне концентраций $\mathrm{Y}^{3+}$ состоят преимущественно из микрокристаллов размером $8-20 \mu \mathrm{m}$, а количество мелких микрокристаллов $(1-2 \mu \mathrm{m})$ крайне мало. Наибольшее количество микрокристаллов размером 1-2 $\mu \mathrm{m}$ $(\sim 1 \%$ от всего объема) наблюдается в образцах $\mathrm{Lu}_{0.84} \mathrm{Y}_{0.15} \mathrm{Eu}_{0.01} \mathrm{BO}_{3}$ (рис. 4, $b$ ), в то же время, этот образец содержит $20 \%$ фазы ватерита (табл. 1), что свидетельствует о том, что основная доля фазы ватерита содержится в микрокристаллах размером $8-20 \mu \mathrm{m}$. Следует также отметить, что прессование таблеток перед отжигом при $970^{\circ} \mathrm{C}$ практически не влияет на морфологию $\mathrm{Lu}_{0.99-x} \mathrm{Y}_{x} \mathrm{Eu}_{0.01} \mathrm{BO}_{3}$, в этих образцах при $0.1<x \leq 0.25$ наблюдаются микрокристаллы размером $8-20 \mu \mathrm{m}$,
На рис. 9, спектры 1-8, представлены спектры люминесценции (СЛ) соединений $\mathrm{Lu}_{0.99-x} \mathrm{Y}_{x} \mathrm{Eu}_{0.01} \mathrm{BO}_{3}$, содержащие $10,15,20$ и 25 at.\% $\mathrm{Y}^{3+}$, при возбуждении светом, соответствующим резонансному возбуждению ионов $\mathrm{Eu}^{3+}\left(\lambda_{\mathrm{ex}}=394 \mathrm{~nm}\right)$, и в максимуме полосы с переносом заряда $\left(\lambda_{\mathrm{ex}} \sim 250-243 \mathrm{~nm}\right)$. СЛ образцов, имеющих согласно данным рентгенофазового анализа структуру кальцита, при $0 \leq x<0.1$ (табл. 1) идентичны. В этих образцах спектры люминесценции приповерхностного слоя $\left(\lambda_{\mathrm{ex}}=250 \mathrm{~nm}\right)$, и объема образца $\left(\lambda_{\mathrm{ex}}=394 \mathrm{~nm}\right)$ совпадают (рис. 9, спектры 1 и 2). Они содержат полосы с $\lambda_{\max }=589.8$ и $595.7 \mathrm{~nm}$, характерные для кальцитной модификации $\mathrm{LuBO}_{3}(\mathrm{Eu})$. В образцах $\mathrm{Lu}_{0.84} \mathrm{Y}_{0.15} \mathrm{Eu}_{0.01} \mathrm{BO}_{3}$, содержащих $80 \%$ кальцита и $20 \%$ ватерита (табл. 1), СЛ приповерхностного слоя содержит только полосы, характерные для кальцитной модификации $\mathrm{LuBO}_{3}(\mathrm{Eu})$ (рис. 9, спектр 3). В то же время, в СЛ объема этих микрокристаллов наблюдаются как полосы, характерные для кальцитной, так и полосы, характерные для ватеритной модификации (588-596, 608-613 и 624-632 nm) этих соединений (рис. 9, спектр 4). Это свидетельствует о том, что фаза ватерита образуется вначале внутри крупных микрокристаллов $(8-20 \mu \mathrm{m})$.

В спектрах люминесценции объема образцов $\mathrm{Lu}_{0.79} \mathrm{Y}_{0.2} \mathrm{Eu}_{0.01} \mathrm{BO}_{3}$, содержащих $10 \%$ кальцита и $90 \%$ ватерита, наблюдаются только полосы, характерные для ватеритной модификации $\mathrm{LuBO}_{3}(\mathrm{Eu})$ (рис. 9, спектр 6). В то же время, СЛ приповерхностного слоя содержит как полосы, характерные для кальцитной модификации $(589.8$ и $595.7 \mathrm{~nm})$, так и полосы, характерные для ватеритной модификации этих соединений (рис. 9, спектр 5). СЛ приповерхностного слоя и объема ортобората $\mathrm{Lu}_{0.74} \mathrm{Y}_{0.25} \mathrm{Eu}_{0.01} \mathrm{BO}_{3}$, имеющего структуру ватерита (табл. 1), содержат только полосы, наблюдающиеся в ватеритной модификации этих образцов (рис. 9, спектры 7,8).

На рис. 9, спектры 9-12, представлены спектры люминесценции образцов $\mathrm{Lu}_{0.99-x} \mathrm{Y}_{x} \mathrm{Eu}_{0.01} \mathrm{BO}_{3}$, предварительно подвергнутых прессованию перед отжигом. В спектре люминесценции приповерхностного слоя образцов ${ }^{*} \mathrm{Lu}_{0.84} \mathrm{Y}_{0.15} \mathrm{Eu}_{0.01} \mathrm{BO}_{3}$, содержащих $52 \%$ кальцита и $48 \%$ ватерита, наблюдаются только полосы кальцитной модификации $\mathrm{LuBO}_{3}(\mathrm{Eu})(589.8$ и $595.7 \mathrm{~nm})$ (рис. 9, спектр 9). В спектре люминесценции объема микрокристаллов ${ }^{*} \mathrm{Lu}_{0.84} \mathrm{Y}_{0.15} \mathrm{Eu}_{0.01} \mathrm{BO}_{3}$ наибольшую интенсивность имеют полосы, характерные для ватеритной модификации этих образцов, в то же время, эти спектры содержат слабые полосы кальцитной модификации этих ортоборатов (рис. 9, спектр 10). Спектры люминесценции объема и приповерхностного слоя микрокристаллов ${ }^{*} \mathrm{Lu}_{0.79} \mathrm{Y}_{0.2} \mathrm{Eu}_{0.01} \mathrm{BO}_{3}$ содержат только полосы, характерные для структуры ватерита этих соединений (рис. 9, спектры 11,12). Согласно данным рентгенофазового анализа эти образцы содержат $4.5 \%$ фазы кальцита и 95.5\% фазы ватерита (табл. 1). 

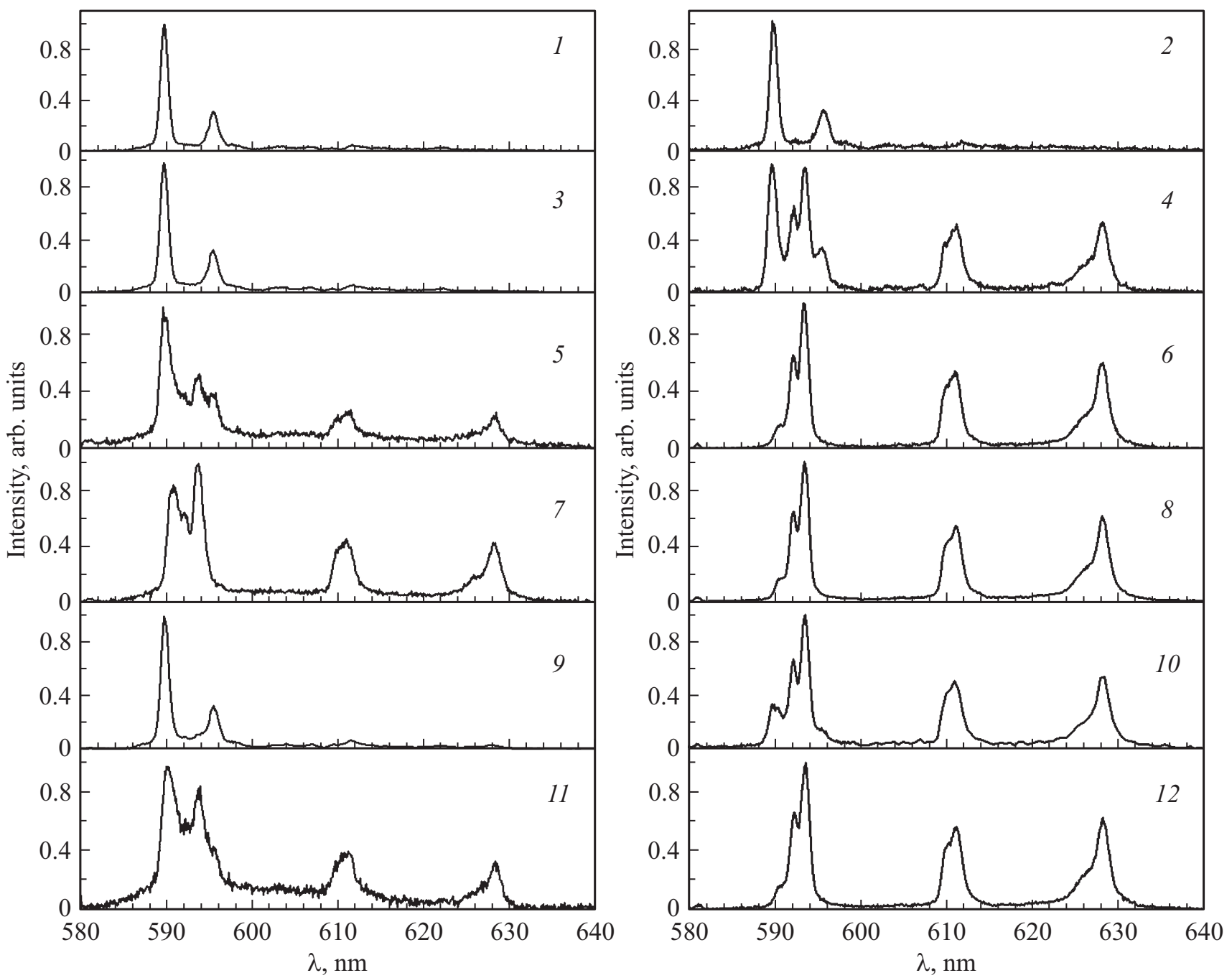

Рис. 9. Спектры люминесценции ортоборатов $\mathrm{Lu}_{0.99-x} \mathrm{Y}_{x} \mathrm{Eu}_{0.01} \mathrm{BO}_{3} .1,2-\mathrm{Lu}_{0.89} \mathrm{Y}_{0.1} \mathrm{Eu}_{0.01} \mathrm{BO}_{3} ; 3,4-\mathrm{Lu}_{0.84} \mathrm{Y}_{0.15} \mathrm{Eu}_{0.01} \mathrm{BO}_{3}$; 5, $6-\mathrm{Lu}_{0.79} \mathrm{Y}_{0.2} \mathrm{Eu}_{0.01} \mathrm{BO}_{3} ; 7,8-\mathrm{Lu}_{0.74} \mathrm{Y}_{0.25} \mathrm{Eu}_{0.01} \mathrm{BO}_{3} ; 9,10-{ }^{*} \mathrm{Lu}_{0.84} \mathrm{Y}_{0.15} \mathrm{Eu}_{0.01} \mathrm{BO}_{3} ; 11,12-{ }^{*} \mathrm{Lu}_{0.79} \mathrm{Y}_{0.2} \mathrm{Eu}_{0.01} \mathrm{BO}_{3 .} .(1,3,9-$

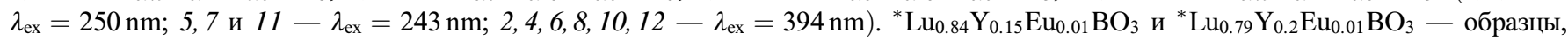
подвергнутые прессованию перед отжигом.

Таким образом, на основании исследования спектров люминесценции приповерхностного слоя и объема ортоборатов $\mathrm{Lu}_{0.99-x} \mathrm{Y}_{x} \mathrm{Eu}_{0.01} \mathrm{BO}_{3}$ можно сделать вывод о том, что при увеличении концентрации $\mathrm{Y}^{3+}$ (при $x>0.1)$ фаза ватерита образуется вначале в объеме крупных микрокристаллов $(8-20 \mu \mathrm{m})$.

Важно отметить, что исследование спектров люминесценции при разных длинах волн возбуждающего света позволяет проследить за процессом формирования структурных модификаций в объеме и на поверхности микрокристаллов исследованных образцов при увеличении концентрации легирующих примесей.

Показано, что спектры люминесценции приповерхностного слоя и объема микрокристаллов $\mathrm{Lu}_{1-x} \mathrm{RE}_{x} \mathrm{BO}_{3}$ $(\mathrm{RE}=\mathrm{Eu}, \mathrm{Tb}$ и $\mathrm{Y})$, имеющих во всем объеме структуру кальцита либо ватерита, совпадают и содержат характерные для этих фаз полосы свечения: для фазы кальцита -
589.8 и $595.7 \mathrm{~nm}$; для ватерита - 588-596, 608-613 и $624-632 \mathrm{~nm}$

Установлено, что в двухфазной области фаза ватерита образуется вначале в объеме крупных микрокристаллов размером 8-20 $\mu \mathrm{m}$, которые имели структуру кальцита. При дальнейшем увеличении концентрации ионов RE фаза ватерита образуется также и на поверхности этих микрокристаллов.

B боратах $\mathrm{LuBO}_{3}$ плотность фазы ватерита $(7.42 \mathrm{~g} / \mathrm{cc})$ заметно больше плотности фазы кальцита $(6.871 \mathrm{~g} / \mathrm{cc})$ [20], поэтому при образовании фазы ватерита в объеме крупных микрокристаллов, имевших структуру кальцита, не будут возникать механические напряжения, препятствующие этому процессу. Так как фаза ватерита имеет меньший объем, то при образовании в микрокристаллах кальцита фазы ватерита, в них образуются пустоты, скопление которых может 
приводить к нарушению сплошности и образованию трещин, которые наблюдаются экспериментально (рис. $3, e, m, n$; рис. $4, c, d, e, f, g, h$ ).

Следует отметить, что при рентгенофазовом анализе мы получаем информацию о структуре образца, усредненную по его объему, поскольку глубина проникновения рентгеновского излучения и максимальный размер исследованных микрокристаллов близки и составляют $\sim 10-15 \mu \mathrm{m}$. В то же время, как отмечалось, структуры на поверхности и в объеме образца могут существенно отличаться [14-16]. Поэтому использование оптически активных и структурно-чувствительных меток, которые дают возможность исследования структуры приповерхностного слоя и объема образца $\mathrm{Lu}_{1-x} \mathrm{RE}_{x} \mathrm{BO}_{3}$ в зависимости от концентрации $\mathrm{RE}^{3+}$, позволяет получать более полную информацию об изменении структурного состояния исследуемых соединений.

\section{7. Заключение}

В настоящей работе проведены исследования структуры, морфологии, ИК-спектров поглощения, а также спектров возбуждения люминесценции и спектров люминесценции приповерхностного слоя и объема синтезированных при $970^{\circ} \mathrm{C}$ микрокристаллов ортоборатов $\mathrm{Lu}_{1-x} \mathrm{Eu}_{x} \mathrm{BO}_{3}$ и $\mathrm{Lu}_{0.99-x} \mathrm{~Tb}_{x} \mathrm{Eu}_{0.01} \mathrm{BO}_{3}$ при $0 \leq x \leq 0.20$, а также $\mathrm{Lu}_{0.99-x} \mathrm{Y}_{x} \mathrm{Eu}_{0.01} \mathrm{BO}_{3}$ при $0 \leq x \leq 0.25$.

Установлено однозначное соответствие между структурной модификацией и спектральными характеристиками фотолюминесценции и ИК-поглощения ортоборатов $\mathrm{Lu}_{1-x} \mathrm{RE}_{x} \mathrm{BO}_{3}(\mathrm{RE}=\mathrm{Eu}, \mathrm{Tb}$ и $\mathrm{Y})$.

Исследование спектров люминесценции при разных длинах волн возбуждающего света позволило получить информацию о структуре приповерхностного слоя и объема исследованных образцов.

Показано, что в ортоборатах $\mathrm{Lu}_{1-x} \mathrm{RE}_{x} \mathrm{BO}_{3}$ $(\mathrm{RE}=\mathrm{Eu}, \mathrm{Tb}$ и $\mathrm{Y})$ увеличение концентрации $\mathrm{RE}$ приводит к последовательному изменению структурного состояния и спектральных характеристик

$$
\begin{aligned}
- & \mathrm{Lu}_{1-x} \mathrm{Eu}_{x} \mathrm{BO}_{3} \text { при } 0 \leq x \leq 0.07, \\
& \mathrm{Lu}_{0.99-x} \mathrm{~Tb}_{x} \mathrm{Eu}_{0.01} \mathrm{BO}_{3} \text { при } 0 \leq x \leq 0.09 \text { и } \\
& \mathrm{Lu}_{0.99-x} \mathrm{Y}_{x} \mathrm{Eu}_{0.01} \mathrm{BO}_{3} \text { при } 0 \leq x \leq 0.1
\end{aligned}
$$

являются однофазными и имеют структуру кальцита $($ пр.гр. $R \overline{3} c)$. Соответствующие этой структуре спектры люминесценции ионов $\mathrm{Eu}^{3+}$ в приповерхностном слое и объеме микрокристаллов этих образцов содержат полосы, характерные для кальцитной модификации $\left(\lambda_{\max }=589.8\right.$ и $\left.595.7 \mathrm{~nm}\right)$.

$$
\begin{aligned}
- & \mathrm{Lu}_{1-x} \mathrm{Eu}_{x} \mathrm{BO}_{3}, \mathrm{Lu}_{0.99-x} \mathrm{~Tb}_{x} \mathrm{Eu}_{0.01} \mathrm{BO}_{3} \text { при } x \geq 0.2 \text { и } \\
& \mathrm{Lu}_{0.99-x} \mathrm{Y}_{x} \mathrm{Eu}_{0.01} \mathrm{BO}_{3} \text { при } x \geq 0.25
\end{aligned}
$$

имеют во всем объеме структуру ватерита (пр. гр. C2/c). Спектры люминесценции ионов $\mathrm{Eu}^{3+}$ в приповерхностном слое и объеме микрокристаллов этих образцов содержат полосы, характерные для ватеритной модификации - 588-596, 608-613 и 624-632 nm.
$-\mathrm{Lu}_{1-x} \mathrm{Eu}_{x} \mathrm{BO}_{3}$ при $0.07<x<0.2$,

$\mathrm{Lu}_{0.99-x} \mathrm{~Tb}_{x} \mathrm{Eu}_{0.01} \mathrm{BO}_{3}$ при $0.09<x<0.2$ и

$\mathrm{Lu}_{0.99-x} \mathrm{Y}_{x} \mathrm{Eu}_{0.01} \mathrm{BO}_{3}$ при $0.1<x<0.25$

являются двухфазными. Они содержат фазы кальцита и ватерита. В спектрах люминесценции наблюдаются полосы, характерные для кальцитной и ватеритной модификаций этих образцов.

Ортобораты $\mathrm{Lu}_{0.99-x} \mathrm{Y}_{x} \mathrm{Eu}_{0.01} \mathrm{BO}_{3}$, имеющие структуру ватерита, состоят преимущественно из микрокристаллов размером 8-20 $\mu \mathrm{m}$, в то время как образцы $\mathrm{Lu}_{1-x} \mathrm{Eu}_{x} \mathrm{BO}_{3}$ и $\mathrm{Lu}_{0.99-x} \mathrm{~Tb}_{x} \mathrm{Eu}_{0.01} \mathrm{BO}_{3}$ со структурой ватерита состоят из микрокристаллов размером $1-2 \mu \mathrm{m}$.

Установлено, что в двухфазной области фаза ватерита образуется как в виде мелких $(1-2 \mu \mathrm{m})$ микрокристаллов, так и в объеме крупных микрокристаллов размером $8-20 \mu \mathrm{m}$, как и в соединении $\mathrm{Lu}_{0.99-x} \mathrm{Gd}_{x} \mathrm{Eu}_{0.01} \mathrm{BO}_{3}$.

Ортобораты $\mathrm{Lu}_{1-x} \mathrm{Eu}_{x} \mathrm{BO}_{3}, \mathrm{Lu}_{0.99-x} \mathrm{~Tb}_{x} \mathrm{Eu}_{0.01} \mathrm{BO}_{3}$ и $\mathrm{Lu}_{0.99-x} \mathrm{Y}_{x} \mathrm{Eu}_{0.01} \mathrm{BO}_{3}$ имеют высокую интенсивность свечения и могут быть использованы в качестве эффективных красных люминофоров для светодиодных источников света

\section{Благодарности}

Авторы выражают благодарность ЦКП Института физики твердого тела им. Ю.А. Осипьяна Российской академии наук за исследование морфологиии образцов, а также их характеризацию методами ИК-спектроскопии и рентгенофазового анализа.

\section{Финансирование работы}

Работа выполнена в рамках госзадания ИФТТ РАН.

\section{Конфликт интересов}

Авторы заявляют, что у них нет конфликта интересов.

\section{Список литературы}

[1] Y.H. Zhou, J. Lin, S.B. Wang, H.J. Zhang. Opt. Mater. 20, 1, 13 (2002).

[2] Jun Yang, Chunxia Li, Xiaoming Zhang, Zewei Quan, Cuimiao Zhang, Huaiyong Li, Jun Lin. Chem. Eur. J. 14, 14, 4336 (2008).

[3] C. Mansuy, J.M. Nedelec, C. Dujardin, R. Mahiou. Opt. Mater. 29, 6, 697 (2007).

[4] J. Yang, G. Zhang, L. Wang, Z. You, S. Huang, H. Lian, J. Lin. J. Solid State Chem. 181, 12, 2672 (2008).

[5] С.З. Шмурак, А.П. Киселев, В.В. Синицын, И.М. Шмытько, А.С. Аронин, Б.С. Редькин, Е.Г. Понятовский. ФТТ 48, 1, 48 (2006)

[6] С.3. Шмурак, В.В. Кедров, А.П. Киселев, И.И. Зверькова. ФTT 55, 2, 336 (2013).

[7] A.A. Mazilkin, O.G. Rybchenko, T.N. Fursova, S.Z. Shmurak, V.V. Kedrov. Mater. Characterization 147, 215 (2019).

[8] С.3. Шмурак, В.В. Кедров, А.П. Киселев, Т.Н. Фурсова, И.М. Шмытько. ФТТ 58, 3, 564 (2016). 
[9] С.З. Шмурак, В.В. Кедров, А.П. Киселев, Т.Н. Фурсова, О.Г. Рыбченко. ФТТ 59, 6, 1150 (2017).

[10] С.3. Шмурак, В.В. Кедров, А.П. Киселев, Т.Н. Фурсова, И.И. Зверькова, С.С. Хасанов. ФТТ 62, 11, 1888 (2020).

[11] С.3. Шмурак, В.В. Кедров, А.П. Киселев, Т.Н. Фурсова, И.И. Зверькова. ФТТ 62, 12, 2110 (2020).

[12] М.А. Ельяшевич. Спектроскопия редких земель. ГИТТЛ, M. (1953). $456 \mathrm{c}$.

[13] М.И. Гайдук, В.Ф. Золин, Л.С. Гайгерова. Спектры люминесценции европия. Наука, М. (1974). 195 с.

[14] А.П. Киселев, С.3. Шмурак, Б.С. Редькин, В.В. Синицын, И.М. Шмытько, Е.А. Кудренко, Е.Г. Понятовский. ФТТ 48, |it8, 1458 (2006).

[15] S.Z. Shmurak, A.P. Kiselev, N.V. Klassen, V.V. Sinitsyn, I.M. Shmyt'ko, B.S. Red'kin, S.S. Khasanov. IEEE Trans. Nucl. Sci. 55, 1-3, 1128 (2008).

[16] С.З. Шмурак, А.П. Киселев, Д.М. Курмашева, Б.С. Редькин, В.В. Синицын. ЖЭТФ 137, 5, 867 (2010).

[17] D. Hrrniak, E. Zych, L. Kepinski, W. Strek. J. Phys. Chem. Solids 64, 1, 11 (2003).

[18] С.3. Шмурак, В.В. Кедров, А.П. Киселев, Т.Н. Фурсова, И.И. Зверькова, Е. Ю. Постнова. ФТТ 63, 7, 933 (2021).

[19] J. Hölsä. Inorg. Chim. Acta 139, 1-2, 257 (1987).

[20] E.M. Levin, R.S. Roth, J.B. Martin. Am. Miner. 46, 1030 (1961).

[21] G. Chadeyron, M. El-Ghozzi, R. Mahiou, A. Arbus, C. Cousseins. J. Solid State Chem. 128, 261 (1997).

[22] С.3. Шмурак, В.В. Кедров, А.П. Киселев, И.М. Шмытько. ФTT 57, 1, 19 (2015).

[23] С.3. Шмурак, В.В. Кедров, А.П. Киселев, Т.Н. Фурсова, И.М. Шмытько. ФТТ 57, 8, 1558 (2015).

[24] .D. Santamaría-Pérez, O. Gomis, J. Angel Sans, H.M. Ortiz, A. Vegas, D. Errandonea, J. Ruiz-Fuertes, D. MartinezGarcia, B. Garcia-Domene, L. André, J. Pereira, F. Javier Manjón, P. Rodríguez-Hernández, A. Muñoz, F. Piccinelli, M. Bettinelli, C. Popescu. J. Phys. Chem. C 118, 4354 (2014).

[25] Wen Ding, Pan Liang, Zhi-Hong Liu. Mater. Res. Bull. 94, 31 (2017).

[26] Wen Ding, Pan Liang, Zhi-Hong Liu. Solid State Sci. 67, 76 (2017).

[27] Zhi-Jun Zhang, Teng-Teng Jin, Meng-Meng Xu, QingZhen Huang, Man-Rong Li, Jing-Tai Zhao. Inorg. Chem. 54, 969 (2015).

[28] А.Г. Рябухин. Изв. Челябинского науч. центра, вып. 4, 33 (2000).

[29] С.3. Шмурак, В.В. Кедров, А.П. Киселев, Т.Н. Фурсова, И.И. Зверькова, С.С. Хасанов. ФТТ 61, 4, 747 (2019)

[30] С.3. Шмурак, В.В. Кедров, А.П. Киселев, Т.Н. Фурсова, И.И. Зверькова, С.С. Хасанов. ФТТ 61, 11, 2142 (2019)

[31] C.E. Weir, E.R. Lippincott. J. RES. Natl. Bur. Std. 65A, 3, 173 (1961).

[32] D. Boyer, F. Leroux, G. Bertrand, R. Mahiou. J. Non-Crystal. Solids 306, 2, 110 (2002).

[33] J.P. Laperches, P. Tarte. Spectrochim. Acta 22, 7, 1201 (1966).

[34] A. Szczeszak, T. Grzyb, S. Lis, R.J. Wiglusz. Dalton Trans., 41, 5824 (2012).

[35] Guohua Jia, Peter A. Tanner, Chang-Kui Duan, Jeannette Dexpert-Ghys. J. Phys. Chem. C 114, 2769 (2010).

Редактор Т.Н. Василевская 